\title{
Undergraduate Research in Economics
}

KimMarie McGoldrick, Department of Economics, University of Richmond, Richmond, VA Published by the Economics Network, May 2007

Online version at http://www.economicsnetwork.ac.uk/handbook/ugresearch/

1 Introduction

2 Reports on Undergraduate Research Specific to Economics

2.1 How widespread is the use of undergraduate research in degree programmes?

2.2 What forms of undergraduate research are being implemented?

2.3 What best practices can be recommended by those who actively participate in undergraduate research?

3 Factors to Consider when Developing a Research Intensive Experience for Undergraduates

3.1 The form of the research process

3.2 The degree to which students are free to select the research topic

3.3 Project formats

3.4 Level of guidance that will be provided

3.5 Skills the project is designed to enhance

4 The Goal: Hansen's Proficiencies

5 The Professor's Role: Seven Principles of Good Practice in Undergraduate Education

$\begin{array}{ll}5.1 & \text { Encourages student-faculty contact } \\ 5.2 & 17\end{array}$

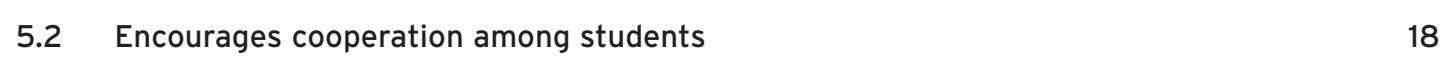

5.3 Encourages students to undertake projects that have personal relevance and interest 18

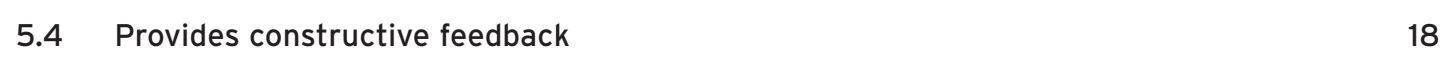

5.5 Emphasises time on task (such as through strict timetables) 21

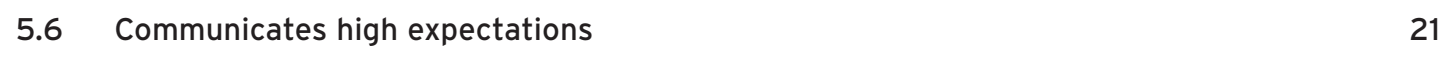

$\begin{array}{lll}5.7 & \text { Respects diverse talents and ways of learning } & 23\end{array}$

$6 \quad$ Evaluating Student Projects $\quad 24$

$\begin{array}{lll}6.1 & \text { Research skills } & 24\end{array}$

6.2 Economic analysis 24

6.3 Communication skills 25

6.4 Getting Students to Evaluate the Quality of their Own Work 26

References and further reading 31 


\section{Introduction}

Undergraduate research is not a new pedagogical practice. Programmes developing such skills have been formally instituted in select disciplines such as the laboratory sciences for decades. In other disciplines, such as economics, formal efforts to engage students in the practice of conducting research have only developed more recently. Models of undergraduate research programmes range from individual to institution-wide efforts. Instructors develop such opportunities by either adding significant research components to their courses, developing entire courses around the research project or overseeing senior theses and independent study projects. Research on the use of active learning techniques suggests that students learn better by doing than by simply listening to an expert tell them how things work (Hake, 1998; Prince, 2004). Thus, it is not surprising that programmes like the Higher Education Funding Council for England's (HEFCE) 'Research Informed Teaching' have recently given added impetus to these innovations.

Undergraduate research experiences are being promoted across the OECD as a route towards improved student learning outcomes. In the United States, the Council on Undergraduate Research's (CUR, http://www.cur.org/about.html) programme was constructed 'to support and promote high-quality undergraduate student-faculty collaborative research and scholarship.' The CUR sponsors multi-day institutes focused on specific issues such as proposal writing, sustaining undergraduate research programmes and institutionalising undergraduate research. It also provides summer fellowships for students and sponsors 'dialogue' conferences that provide participants with opportunities to learn about and interact with agents representing funding agencies. Although focused more broadly on undergraduate education in the United Kingdom, the Higher Education Academy provides a variety of supporting activities for undergraduate research. For example, it has supported the development of the Centre for Excellence in Teaching and Learning 'Reinvention Centre for Undergraduate Research' at the University of Warwick, the aim of which is to put 'undergraduate research at the centre of undergraduate education' (http://www2.warwick.ac.uk/fac/soc/sociology/research/cetl/ ugresearch/). The University of Sydney's USYD program (http://www.itl.usyd.edu.au/RLT/ usydproject/about.htm) includes as one of its project objectives 'to extend opportunities for students at all levels to experience and conduct research, learn about research throughout their courses, develop the skills of research and inquiry and contribute to the University's research effort (Research-based learning).'

There is much research yet to be completed before we draw conclusions about the degree to which undergraduate research programmes are effective. Although those who oversee undergraduate research opportunities generally agree that the expected outcome is for students to 'understand a research problem in sufficient depth so as to be able to pose a question about it, determining what evidence is needed to solve the problem, and collecting data that will answer the question' there is less consensus on how these outcomes are to be assessed (Kardash, 2000: 191). Rueckert (2002: 10-11) suggests that research measuring learning outcomes needs better use of control groups, development of longitudinal studies and less of a reliance on indirect measures of student learning such as self-report data and student perceptions when conducting research on the effectiveness of this pedagogical technique.

Despite these shortcomings, the existing research does provide interesting insights as to the impact of undergraduate research on student participants. Using four institutions and a number of survey methods, Lopatto (2006: 23) concludes that 'students reported gains on a variety of 
skills, including design and hypothesis formation, data collection and interpretation, information literacy, communication, and computer work.' Hathaway et al. (2002) find that students who participate in undergraduate research projects are more likely to attend graduate school although sample selection issues might suggest that these students were predestined to continue their education through participation in such programmes. Benefits can also be linked to the acquisition of a wide range of skills including analytical, communication and higherorder thinking skills that benefit all students. In a study of engineering and science students participating in undergraduate research projects during a ten-year period, Ward et al. (2003: 1) found that students 'reported increased technical skill, ability to act independently, insight into graduate and career possibilities, understanding of the value of team work, ability to work with setbacks and/or ambiguity, desire to learn, ability to think creatively and/or synthetically, self confidence, communication skills, and an understanding of where 'knowledge' comes from.' Less skill-oriented benefits are often overlooked. For example, Nagda, et al. (1998) find that those who are at the highest risk for college attrition (African American students and those with low GPAs) are more likely to be retained when faculty-student research partnerships are formed.

The main goal of this chapter is to introduce readers to some of the many important issues that should be considered when developing undergraduate research experiences. These include, but are not limited to, tensions between:

- development of detailed knowledge and skills in manipulating economic models and rich contextual understanding that may arise from discussion of a variety of social science perspectives; and

- deep understanding of a limited range of economic models and more superficial understanding of a broader range of models.

Curriculum decisions about the extent of research requirements, the degree of freedom of choice of research topic and the extent to which students are expected to restrict their definition of problems and choice of methods to econometric tests of economic hypotheses will strongly influence the response to these tensions.

In addressing these and other issues, this chapter does not present a prescriptive 'one size fits all' model of undergraduate research; rather, it is designed to encourage instructors to be purposeful in their own design and evaluation of such experiences. In order to motivate this process, the rest of this chapter includes sections describing the research that exists on this topic, key factors to consider when developing a research intensive experience, expected skills developed, the professor's role and issues of evaluation. Each section is designed so that readers can move throughout the chapter in any order they wish. (Although this does result in a few instances of repetition, each case occurs in a different context and is therefore not solely repetitive.) Despite this seemingly independent nature of the presentation of this material, each section is critical to the development of undergraduate research projects and thus the reader is encouraged to review all sections. 


\section{Reports on Undergraduate Research Specific to Economics}

\subsection{How widespread is the use of undergraduate research in degree programmes?}

Although no research exists documenting the degree to which institutions require undergraduate research in economics, one recent survey documents the characteristics of writing requirements, honours programmes and capstone/senior experiences at institutions in the United States (McGoldrick, 2006). Results of this survey indicate that 70 per cent of institutions have a formal writing requirement and the most popular form is a senior seminar with a significant writing component. These senior seminars are typically low enrolment courses designed to allow students to strengthen their knowledge of a particular field of economics and practise their application of the subject matter. Because of the labour-intensive nature of such courses, they are more likely to exist at smaller institutions where the faculty to student ratio is higher. These smaller schools are more likely to require writing and subsequently are also more likely to see improvements in students' writing skills. On average, students are assigned four research papers by the time they graduate no matter what type of institution they attend. More than one third of the institutions offer honours programmes which typically require a minimum GPA, a research paper, and an oral presentation. Capstone courses are typically situated in the final year of the student's educational programme and are designed around students demonstrating their mastery of the content and application of economic theory. Survey results suggest that capstone/senior experiences occur at 60 per cent of institutions and most likely in the form of a course. Courses that are dedicated to the research process require students to apply the tools they have mastered to a specific research issue. These experiences are designed to stimulate an independent and economic way of thinking and to teach students how to synthesise the literature. Such courses typically expose students to new, policy-oriented topics and provide specific exercises to teach the components of the research process. Overall, about one half of the institutions reported that students' work had been published in both professional academic and student journals although this was slightly less likely for students who participated in a capstone/senior experience course rather than the honours programme. For additional information about capstone courses, refer to the case studies associated with this chapter.

\subsection{What forms of undergraduate research are being implemented?}

Most of the documented descriptions of undergraduate research projects in economics come in conjunction with a senior/capstone experience course. These include courses in which the instructor and students complete research projects linked to specific course content (McElroy, 1997), use the literature of distinguished economists to link economics to general education through written and oral presentations (Elliott, Meisel and Richards, 1998), devise a detailed description of the components of a successful honours programme (Siegfried, 2001), use the May issue of the American Economic Review in a seminar format to develop skills that contribute to success in an analytical project (Elliott, 2004), and a capstone research course that allows students to choose their topic without restriction (McGoldrick, 2006). A brief description of this latter project is provided as the first case study in this chapter. 
Other forms of undergraduate research are integrated throughout the curriculum. One such example incorporates service-learning into a course (McGoldrick, 1998). Service-learning projects require students to spend time in volunteer service and relate their experiences with the theories they learn in the classroom. Unlike classroom exercises and simulations that often deal with hypothetical problems, service-learning provides students with ample opportunities to engage with the material in the context of actual issues and problems in their communities. This pedagogical technique is also unique in that it requires students to actually perform activities that economists would perform. The service component implies that a product is generated that the community can use whereas the learning occurs when students put their economic skills to work to analyse a problem in conjunction with the community. During the service-learning project students identify economic issues, formulate hypotheses, gather evidence, develop economic explanations, link evidence relating their experiences with these economic theories and make policy recommendations. Thus, service-learning suggests an active approach to learning economic theory and conducting research. A brief description of a service-learning course is provided as the second case study in this chapter.

Most other descriptions of undergraduate research projects that are not specific to senior/capstone seminar classes focus on integrating significant writing assignments into courses. Simpson and Carroll (1999: 406) provide an interesting perspective on the success of such writing assignments. They surveyed alumni in an attempt to determine what forms of writing assignments enhanced an understanding of economics in addition to a simple focus on writing skills. Their results suggest that while shorter writing assignments (analysis of reading, opinion papers and letters) enhance skills associated with professional life, it is the longer research paper requiring analysis that is more effective for learning economics.

\subsection{What best practices can be recommended by those who actively participate in undergraduate research?}

In a recent panel discussion held at the Southern Economic Association meetings (in November 2006), five faculty provided their perspectives on 'Best Practices for Undergraduate Research'. Steven Greenlaw and KimMarie McGoldrick presented results of a preliminary survey designed to document the extent and form of undergraduate research initiatives by faculty in the United States. Their study (albeit preliminary and based on a small sample) suggests that undergraduate research is more likely to occur at institutions with small classes, to be promoted by faculty who have more experience in the classroom, and to be dominated by policy-oriented and empirical projects that occur in senior/capstone experience courses.

Participants in this research session provided advice (not unlike that suggested by the survey conducted by Lopatto, 2003) in determining the essential features of undergraduate research from both the faculty and student perspectives. A highly structured environment including expectations, assignments and due dates should provide the organisational structure for the project. Student research should be grounded in primary source literature and linked to students' previous work. In the design of their project, students should have ownership and be encouraged to be creative. The research question that is developed should be narrowly focused and research should be conducted in a highly structured environment. Finally, students should be prepared to communicate their results in both oral and written formats. 


\section{Factors to Consider when Developing a Research Intensive Experience for Undergraduates}

The guidance that is provided to students is crucial for the effectiveness of an undergraduate research programme. A first step is to agree upon a common strategy across the faculty. Explicit choices must be made regarding:

- the form of research process to be encouraged,

- the degree to which students are free to select the research topic,

- project formats that will be acceptable,

- level of guidance that will be provided, and

- skills the project is designed to enhance.

\subsection{The form of the research process}

Although it may seem elementary to define the research process, it is a logical first step in developing an undergraduate research experience. By defining the process through a series of key components, one can begin to identify important issues that must be resolved when developing projects. For the purpose of discussion, let us assume the definition of the research process in Figure 1.
Figure 1 Steps in the Research Process
1. Identify economic issues
6. Develop evidence
2. Develop a research question
7. Draw conclusions
3. Undertake a literature search
8. Compare conclusions to identified literature
4. Summarise relevant literature
9. Apply analysis to current policy issue
5. Identify an area of potential contribution
10. Present research to peers and/or faculty

Before proceeding to a discussion of some of the key aspects associated with each of these steps in the research process, a number of general issues should be kept in mind throughout this discussion. Although papers are typically structured in a traditional format starting with an introduction, this does not imply that the process of developing a final product should be conducted in that same order. In fact, students who try to write their introduction before their analysis is conducted often find themselves having to completely rewrite it because the focus of the paper has shifted from their initial conceptualisation. Students also need to understand that there are two audiences for their work. The final product should be of interest to their peers while also demonstrating students' competencies to the instructor. Traditional instructor feedback might be complemented with peer review. Furthermore, feedback provided throughout 
the process should be both formative and summative so that students learn how to interpret critical comments and incorporate changes. Using the revise and resubmission method that is standard in our own process of research allows instructors to nurture students' understanding and skills. These issues of evaluation are developed in greater detail in the 'Evaluating Student Projects' section of this chapter.

\section{1 .1 Identifying economic issues}

Students typically bring many interests to the research process. In fact, getting them to narrow their interests to a single economic issue can be quite a challenge. It is important to have students distinguish between choosing a topic and identifying an economic issue. For example, a student might be interested in labour economics as a topic but their research issue must be much more narrow. For example, they might analyse the degree to which gender affects compensating wage differentials.

\subsubsection{Developing an effective economic research question}

Once students have settled on a viable topic and issue, they must narrow their focus by developing a research question. Students typically have the capacity to generate a lot of interesting questions with respect to a topic, but developing an effective question is a much more difficult task which will determine the success of the research. Effective economic questions have distinct characteristics that can be directly linked to the research process. Greenlaw (2006: 14-18) suggests that effective economic questions are problem-oriented, analytical, interesting and significant, amenable to economic analysis and feasible. Figure 2 provides examples of first attempts made by students at developing effective economic questions. Along with each question is an evaluation of the degree to which the criteria for an effective economic question are satisfied.

\section{Figure 2 Developing Effective Economic Questions}

Criteria:

- Problem-oriented: to focus the question in a meaningful way the question is framed in the form of a problem to be addressed rather than a question that can be answered with a simple yes or no.

- Analytical: the question should drive the researcher to explain rather than describe a problem.

- Interesting and significant: in order to encourage the researcher to produce exemplary work and to engage the audience.

- Amenable to economic analysis: what insights can be gained from applying economic analysis to the question at hand?

- Feasible: can the proposed question be answered in the given time allotment?

Topic and Questions

Effective? Evaluation: criteria not satisfied

Topic: Consolidation in the Public

Accounting market, specifically in

the area of external audit
1. Is the public accounting market longer competitive due to consolidation?
2. Does the public accounting market be need to be competitive?
1. no $\quad$ Not problem-oriented.
2. no Not analytical, this question is opinion based. 


\section{Topic and Questions \\ Effective? \\ Evaluation: criteria not satisfied}

Topic: Economic Impact of Hurricane Katrina

1. Will the US economy continue to 1 . no scuffle in the wake of Katrina or will

1. Not problem-oriented, analytical, reconstructive efforts provide the projected boost?

2. How much will the reconstruction effort cost and will that be larger than the benefits given the characteristics of New Orleans?

\section{Topic: An analysis of the US Film Industry}

1. Do certain critics' reviews have an influence on the demand for a film

1. potentially

1. More detail needs to be provided. to define what is meant by 'certain critics' and 'influence'

2. An analysis of the American Film Industry during the 1990 s.

2. Not problem-oriented or feasible. in the box office?

2. Not problem-oriented, analytical, amenable to economic analysis or feasible.

Topic: The economic and environmental implications of agricultural subsidies

1. What are the economic and

1. no

1. Descriptive rather than analytical. environmental implications of California's Central Valley Project?

2. Do the economic and environmental costs of direct payment agricultural subsidy programmes outweigh the benefits?

2. potentially 2 . The issue of concern is feasibility; namely, can these costs and benefits be measured? Also, this would need to be rephrased to make it more problemoriented.

\section{Topic: Tort reform and its effects on California compared to various other states}

1. Will tort reform considerably change the malpractice environment?

2. Why has tort reform in California changed the malpractice environment?
1. no

2. potentially
1. The question is not problem-oriented and it is not clear what analysis would be used

2. It is not clear what is meant by the malpractice environment and thus hard to judge whether it is problem-oriented or analytical.

\section{Topic: The spa industry in relation to the small business world}

1. Why has the recent boom in spa 1. yes attendance started to decline?

2. What are the most significant economic 2. no factors in creating a successful spa?
1. Fits all criteria, but care must be taken to make sure this is analytical and not descriptive

2. Descriptive rather than analytical.

\section{Topic: AIDS in South Africa}

1. How does the incidence of HIV/AIDS 1. yes 1. Fits all criteria. in South Africa affect its GDP?

2. How does the AIDS epidemic in South 2. yes $\quad 2$. Fits all criteria. Africa affect its human capital and labour supply? 
Topic: Whether or not increasing the amount of domestically produced oil, particularly in the Alaskan National Wildlife Preserve, would economically benefit the United States

1. How has the price of oil affected indicators of economic well being such as the unemployment rate and the GDP in the United States over the past decade?

2. How would drilling in the Alaskan National Wildlife Preserve (ANWR) affect the United States' reliance on foreign oil?
1. potential

1. The problem is whether this question is feasible and to what extent a micro change (price) can be used to explain macro conditions.

2. yes 2. Fits all criteria.

Topic: How are baseball players valued based on the MRP they bring to their respective teams How effective is the MLB free-agency market in efficiently valuing players?
1. Why are some MLB small market
1. yes
1. Fits all criteria.
teams continually competitive
2. Fits all criteria, but care must be (i.e. Oakland Athletics) while others are not (i.e. Pittsburgh Pirates)? taken to make sure this is analytical and not descriptive.

Topic: The possibility of an organ market and the effect it would have on both the number of donors and the recipients waiting for organs.
1. Would an open market for organs be an effective alternative to the 1. no present allocation techniques?
1. Not problem-oriented, analytical, or feasible.
2. What impact would restitution for donation of organs have on the overall supply of organs?

The examples provided in Figure 2 underscore the general lack of understanding that students have regarding the development of an effective research question and thus practise with existing questions can help. Requiring students to read papers that model acceptable formats for completed research (such as traditional quantitative analyses, historical perspectives, analysis of contemporary economic issues, comparing alternative viewpoints in economics, and community-based projects) and identify the key question is a valuable first step. Alternatively, students can be provided with a list of economic questions (such as first and final drafts of questions from student projects in previous semesters) and be asked to evaluate each question to demonstrate their comprehension of the characteristics. After a bit of practise in evaluating questions and developing a richer understanding of effective economic research questions, students can be asked to develop and justify their own questions.

\subsubsection{Undertaking a literature search, summarising the literature and identifying an area of potential contribution}

The completion of a well-developed literature review requires that a student demonstrates skill in locating and summarising publications that are key to their project. Unless guided to do otherwise, students are likely to rely on general internet searches to locate literature. Using academic search engines such as EconLit and Google Scholar, accessing working paper series that are available online such as the National Bureau of Economic Research (www.nber.org) and NetEc (http://netec.wustl.edu/NetEc.html), and searching more general resource sites such as Resources for Economists (http://rfe.org) will greatly enhance the probability of finding appropriate sources. Students readily pick up the skills associated with search techniques 
specific to the economics literature.

The literature review for an undergraduate research project is, arguably, different from those of professional researchers because it will be addressing a different audience - instructors/tutors and peers:

- The literature review will be used by tutors to assess students' understanding of the arguments and evidence presented in the literature. A literature review in a published article might be expected to be more truncated, demonstrating appreciation of the breadth of the field and locating research questions in the context of previous work. Published authors are generally not expected to demonstrate their understanding of arguments they refer to, only to avoid misrepresentation. Thus, a guide suggesting what details should be included for each article reviewed may include the article's main question, evidence provided, caveats, conclusions and relevant policy arguments.

- Tutors may also wish to assess students' ability to relate their research findings to public debate and to communicate economic analysis to a range of audiences and the student peer group provides a practicable opportunity to assess this capability. For these reasons it might be helpful for students to refer to some non-academic sources (such as newspapers) in their literature review. Allowing the review to include popular press sources and interdisciplinary perspectives will help develop peer interest in the more narrowly focused analytical section of the paper. Inclusion of these alternative sources suggests, however, that students also develop skills in evaluating the reliability of such sources.

For more advanced undergraduate research projects that expect students to contribute to the knowledge base in economics, the review presents an additional challenge. Despite their skill at synthesising literature, students are more likely to struggle with the second goal of a literature review: providing a launching point for their own analysis and contribution. Students are much less practised at critiquing the process used by professionals, providing alternative interpretations of results generated and finding gaps in the literature that are ripe for exploration. Building off the modelling process in developing an effective economic question described above, students can use the same model articles to practise these critiques in cooperative settings.

\subsubsection{Develop evidence}

Research projects that require students to perform original work have an added set of hurdles to overcome. As those who practise the art of research on a regular basis, we often take for granted the process of analysis that is used in a research paper. Students, on the other hand, are likely to be facing this process for the first time and thus it is natural for them continually to fall back on what others have done rather than presenting original evidence and arguments. Convincing the audience of the validity of claims depends on the reasoning process employed and the evidence presented. Although most of the research that undergraduates attempt is applied empirical research and thus inductive in nature (using specific cases to reason out a general rule), both deductive (moving from general to specific) and warrant-based arguments (using underlying assumptions to make links between evidence and claims) can be employed as alternative methods of analytical reasoning (Greenlaw, 2006: 57-59).

Students also need to develop an understanding of these methods of reasoning and appreciate that audiences must be convinced by the evidence that is presented. Modelling this process using papers that are exemplars of acceptable formats will provide opportunities for instructors to address each of these issues. Students can be asked to break down the analytical section of a paper to identify the key components of the process and describe the evidence used. They can argue why they think the evidence presented is, or is not, sufficient and the degree to which evidence is open to alterative interpretations. The nurturing of students through this process 
provides them with the necessary understanding to attempt their own analysis. Figure 3 demonstrates a set of model questions that can be used to facilitate this process. Students are asked to read a model article and answer a series of questions that require them to identify the process of answering an effective economic question. A majority of the class discussion that is used as a follow-up activity to this assignment focuses on the types of evidence and the answer to the economic question. Students are placed into groups and asked to compile a comprehensive list of the evidence they have identified in the article. The final, and probably hardest, component is to have students begin to evaluate the evidence in terms of the degree to which it sufficiently answers the question posed and to identify potential caveats to the authors' argument.

\section{Figure 3 Developing the Evidence}

The assignment:

Read KimMarie McGoldrick and Lisa Ford Voeks (2005) “ 'We Got Game!' An Analysis of Win/Loss Probability and Efficiency Differences between the NBA and WNBA", Journal of Sports Economics, Vol. 6(1), pp. 5-23.

http://jse.sagepub.com/cgi/content/abstract/6/1/5

\section{Goal of this assignment:}

Look at Greenlaw's Table 2.1 (page 13) that describes "The Research Process in Economics" and the corresponding text. The WNBA is an example of an empirical paper and was developed in exactly this fashion. By discussing a research paper so early in the semester you will be more familiar with some of the components that you will need to complete in your own work. Thus, we will use this work to show an overview of the research process. I will also be discussing some of the hurdles that we had to overcome in conducting this research.

\section{Questions:}

1. Provide a general description (3-4 sentences) of the purpose of this paper.

2. What is the economic question that the authors are attempting to answer? Can you locate this specifically in the text? Where? What sub-questions are used to answer this main question? List these.

3. What contribution to the literature does this paper make?

4. What type of evidence does this paper provide in answering the economic question? Is this form of evidence consistent with that found in cited literature?

5. Is the evidence convincing? Here you want to consider how much evidence is presented, the extent to which proxies are used, whether the data is complete or restricted in any way, etc. What additional evidence would add to the story told by the authors?

6. What is the answer to the economic question? Can you locate this specifically in the text? Where?

7. What was most confusing about the paper? Be specific and, if possible, provide page numbers.

8. What was most clear about the paper? Be specific and, if possible, provide page numbers.

9. Construct a well-detailed outline of this paper on a separate sheet of paper (typed). Bring two copies to class. Please note that a good outline does not have complete sentences and is detailed enough that you could actually write the paper from it if necessary.

We must allow for the possibility that a student may demonstrate good understanding and practice in the research process without managing to gather and analyse data that support their original hypothesis. Such 'failures' may turn out to be excellent learning experiences and students can be encouraged to use these as opportunities to develop a critical analysis of their own work in their conclusions. 


\subsubsection{Draw conclusions and compare conclusion to identified literature}

Many students tend to use the final section of the research project to summarise key points already made in the body of the paper. A conclusion section should challenge students to place their work in the context of the larger body of knowledge. This requires that they first conduct critical reflection regarding the evidence that they have presented. Are proxies used in their analysis satisfactory? Does the evidence support their hypothesis? How does it compare to other conclusions in the literature on this topic? Is there an alternative interpretation? In light of these caveats, students should also be required to identify questions that remain unanswered and to indicate what they regard as priorities for further research. These observations might be linked specifically to what they would do if they had more time.

In order to facilitate this process, a few exercises can be implemented throughout the semester in order to model the critical thinking we wish to see in students' conclusions. For example, when they are assembling their evidence students can be asked to develop a three-column table. The first column contains a description of each piece of evidence that when aggregated would be sufficient to support their claims. The second column would identify what ideal variables would measure, describe or quantify. The final column would list the actual data they have for each piece of evidence. By comparing the second and third columns of this table, students can begin to develop a sense of the extent to which they must state caveats to their research and suggest alternative explanations that cannot be ruled out given the limitations of their evidence.

\subsubsection{Apply analysis to current policy issue}

The value of doing research can be demonstrated to students through its connection with policy recommendations. In order to encourage students to begin making policy connections early in their research, one might implement a modelling exercise directly after the literature review section of their paper is complete. Students can be asked to identify all the relevant policy arguments included in the research cited in their review. A summary of these policies and the extent to which they might also apply in their own work can be a follow-up exercise that is used later when developing the conclusion.

\subsubsection{Present research to peers and/or faculty}

Effectively communicating key components of conducted research in front of peers and faculty may not be a comfortable task for students. Students often fall into the trap of trying to communicate everything they have done in a step-by-step description of their work rather than conveying the meaning of their findings. It is usually helpful to provide guides to the processes of summarising research and developing complementary visual aids. One logical starting point is for students to make a detailed outline of their paper and to use this as a guide for what to include in the presentation. As with professional presentations, however, one cannot hope to include all the work that has been completed for the project. Recommending that each subsection of the paper be limited to one or two visual representations (such as an overhead or PowerPoint slide) with no more than four points on each is one step toward avoiding the problem of overwhelming presentations. Students should also be reminded of the need to keep their audience focused on key aspects of their work: the economic question, the way in which their question is related to previous work, the analysis of their evidence and their conclusions.

\subsection{The degree to which students are free to select the research topic}

Allowing students to research topics that capture their interest and which they believe are 
relevant to them makes sense if we wish to develop optimal motivation for their effort. Because most students are novices in the research process, it is tempting to skip this and provide a list of research ideas from which students can choose. This is especially likely if the project is developed for a course with a prescribed set of topics. Although providing topics allows students to get a jump start on their research, there is a strong likelihood that the student will not have a passion for the topic. Alternatively, students can be asked to develop their own research topic. While this freedom of choice can occur with projects developed for topic-driven elective courses, it is more likely in the case of an independent study, a senior thesis or a capstone course dedicated to the research process. The advantage of free choice is that it allows students to be creative in the development of topics that may be interdisciplinary, introduce new topics not covered in currently offered courses or serve as extensions of their own past work. The downside of this choice is that it also requires students to overcome a significant hurdle: narrowing their interests to a single topic.

\subsection{Project formats}

One might broaden the scope of the undergraduate research experience by encouraging students to reflect on what economists actually do. Essentially economists discover, develop and promote the knowledge and study of economics through the varied facets of academic life. This process is aptly captured in the words of Boyer (1990: 24), 'knowledge is acquired through research, through synthesis, through practice and through teaching', which he defined as the scholarships of discovery, integration, application and teaching, respectively. While it is clear that, as professional economists, we actively partake in these forms of knowledge acquisition, Boyer (1997: 79) suggests 'the redefinition of scholarship might also be appropriate for students. Why not have all incoming students join with the faculty right away as young scholars in the discovery of knowledge, in the integration of knowledge, in the application of knowledge, and in the communication of knowledge? Why not have these four dimensions of scholarship become the four essential goals of undergraduate education?'

Explicitly identifying steps of the research process can stimulate discussion of alternative

methods of conducting research. Students are more likely to develop an understanding of the methods of research traditionally used by economists if they are aware of alternatives that could be adopted. Comparison of methods facilitates critical reflection that is usually a stated outcome of degree programmes. Comparison of this kind might be provided through examples taken from heterodox literature.

\subsection{Level of guidance that will be provided}

Students come into the research process equipped with varying skills. The degree to which students are allowed to develop their projects independently depends on their maturity to tackle such an undertaking. Issues that need to be considered regarding the level of guidance include:

- determining the degree to which the research process will be demonstrated to students through specific exercises;

- choosing the number of intermediate points of evaluation at critical junctures (such as the effective economic question, situating current research in past literature, developing and analysing the evidence, and the conclusion); and

- the degree to which face-to-face meetings will be conducted to guide and push students to do better research.

While it might appear that senior research theses or capstone courses are the time at which 
more independence can be assumed, this depends entirely on the degree to which students have developed the necessary skills in previous courses.

\subsection{Skills the project is designed to enhance}

Because the undergraduate research project can be developed at many levels of the curriculum, it is important to identify specifically what skills the project is being designed to enhance. Although one might expect students to be proficient in accessing existing knowledge, displaying command of that knowledge, providing both theoretical and empirical interpretations, applying knowledge, asking pertinent and penetrating questions, and creating new knowledge (Hansen, 1986) by the end of their undergraduate studies, courses throughout their studies introduce and develop each of these skills. For example, in an industrial organisation and public policy course a research project that focuses on displaying command of existing knowledge might require students to conduct a review of literature in a single industry to determine its structure, firm conduct and economic performance in support of a determination of the position of that industry on the competitive-monopoly market continuum. More detailed discussion of skills development is found in the following section.

\section{The Goal: Hansen's Proficiencies}

According to Hansen (1986: 231) graduates in economics should be 'effectively equipped to use their knowledge and skills.' They should be proficient in accessing existing knowledge, displaying command of that knowledge, providing both theoretical and empirical interpretations, applying knowledge, asking pertinent and penetrating questions, and creating new knowledge. Hansen (2006) has developed a taxonomy (Figure 4) to describe these skills in more detail and this offers a well-defined structure on which to ground the undergraduate research process. The advantage of reviewing these proficiencies in conjunction with the development of an undergraduate research project is two-fold. First, it serves as a reminder for instructors of the many ways that projects can be designed that focus on specific skills. Second, this rubric can be used as a guide for assessing the degree to which students have participated in the skill development necessary to take on larger projects. 


\section{Figure 4 Grounding a Model of Undergraduate Research in Hansen's Taxonomy} of Learning

Key Steps in the Undergraduate Research Model Hansen's Proficiencies for the Economics Major

1. Identify economic issues

Accessing existing knowledge: Locate published research in economics and related fields; locate information on particular topics and issues in economics; search out economic data as well as information about the meaning of data and how they are derived

2. Develop a research question

Asking pertinent and penetrating questions.

Demonstrate an understanding of questions that stimulate productive discussion (factual, interpretative and evaluative) and that reflect particular concerns when engaged in discussing economic issues and policies.

3. Undertake a literature search

Displaying command of existing knowledge:

4. Summarise relevant literature

Write a precis of a published journal article; summarise in a two-minute monologue or a 300 -word written statement what is known about the current condition of the economy; summarise the principal ideas of an eminent economist; summarise a current controversy in the economics literature; state succinctly the dimensions of a current economic policy issue; explain key economic concepts and describe how they can be used.

4. Summarise relevant literature Interpreting existing knowledge:

5. Identify an area of potential contribution

Explain what economic concepts and principles are used in economic analyses published in articles from daily newspapers and weekly news magazines; read and interpret a theoretical analysis, which includes simple mathematical derivations, reported in an economics journal article.

7. Draw conclusions

8. Compare conclusions to identified literature

Applying existing knowledge: Prepare a five-page written analysis of a current economic problem; prepare a two-page decision memorandum for a superior that recommends some action on an economic decision faced by the organisation; write an op-ed essay on some local economic issue.

10. Present research to peers and/or faculty

Creating new knowledge: Identify and formulate a question or series of questions about some economic issue that will facilitate its investigation; prepare a five-page proposal for a research project; complete a research study with its results contained in a carefully edited 20-page paper. 
As Figure 4 demonstrates, proficiencies can be directly associated with the steps that are the focus of an undergraduate research project such as those described in section 3 of this chapter. For example, the first step in this process, identifying economic issues, requires that students demonstrate their mastery of the foundational knowledge in economics. In the language of the proficiencies students must access existing knowledge. This is true regardless of the extent to which students are allowed to determine their own topic for study. In order to translate the chosen topic into a researchable question, students must be able to ask pertinent and penetrating questions. Greenlaw (2006: 14-18) suggests that an effective economic question has welldefined components: problem-oriented, analytical, interesting, significant, amenable to economic analysis and feasible.

One added benefit of using Hansen's proficiencies to ground undergraduate research rests in the many ways each proficiency can be demonstrated, also indicated in Figure 4. As the reader will note, the examples provided by Hansen involve many forms of undergraduate research ranging from short projects (such as five-page written analysis of a current economic problem) to those that could be the focus of an entire course (such as a research study with results that are contained in a 20-page paper).

Basing the undergraduate research process on expected skill development through the proficiencies taxonomy also supports a model of the research process that branches out beyond traditional empirical research that dominates the professional practices in economics. Three examples in which this nontraditional approach to research can be nurtured are encouraging interdisciplinary study, developing qualitative projects and understanding the role of heterodox critiques. The proficiency 'accessing existing knowledge' explicitly suggests that students should locate published research in economics and related fields, which reinforces the prospect of interdisciplinary research that allows students to link economics to other disciplines that they are exposed to during college. The use of qualitative data is often argued to enrich understanding of problems as it allows for historical and social influences that are less easily captured in standard quantitative sources (see, for example, Berik, 1997 and Russell, 2005). The research process outlined in Figure 4 could be enhanced to allow for qualitative projects simply by broadening the data analysis step to include an understanding of how to use qualitative information (as gathered from open-ended questions and interviews, for example). Further, the process of implementing the proficiencies can be adapted to those who are supportive of some of challenges to economics presented by heterodox economics. For example, one would expect that asking penetrating and pertinent questions would be an ideal place in which to incorporate the challenges by feminists and supporters of critical realism in economics. (Some readings that bring a heterodox perspective into the classroom and can be used to develop such questions can be found at http://www.orgs.bucknell.edu/afee/HetReadings.htm.)

Finally, it is important to recognise that a simple presentation of expected outcomes, such as sharing the proficiencies with students, is unlikely to generate the desired result: a welldeveloped research project. The structure of the research project presented to students must be reviewed to ensure that it supports the development of the skills desired. For example, one should not expect students to be able to develop an effective economic question if no part of the research process teaches them to recognise and construct pertinent and penetrating questions. Students must be provided with the opportunity to practise each of these skills in order to become proficient at them, hence the importance of modelling the research process. 


\section{The Professor's Role: Seven Principles of Good Practice in Undergraduate Education}

Nurturing students through the undergraduate research process is a critical component for their success and therefore the role that faculty play in this process is of utmost importance. Recall that our own research skills have been honed through many years of experience and informed by guidance from colleagues. It is important to provide similar guidance for novices that lack experience or critical skills. The goal of this section is to show how 'seven principles of good practice in undergraduate education' (Chickering and Gamson, 1991) can be used as a guide for enhancing the outcomes associated with undergraduate research projects. The examples are drawn from my experience and many of them derived from teaching a capstone research course in economics to undergraduates.

The 'seven principles of good practice in undergraduate education' were developed over 25 years ago through a series of cooperative efforts and were intended to synthesise decades of research on the undergraduate experience. They are designed to provide (Gamson, 1991: 7) an 'accessible, understandable, practical, and widely applicable' list 'of key principles which characterize the practices of educationally successful undergraduate institutions.' Although they were not created to evaluate specific pedagogical practices, subsequent applications of these principles include evaluating the educational goals of entire fields such as legal education, evaluating online courses and using technology (see Hess, 1999; Graham et al., 2001; and Chickering and Ehrmann 1996, respectively). The purpose of introducing them here is that they provide a guide for developing productive practice that is grounded in decades of research on successful pedagogy. The principles are outlined in sections 5.1 to 5.7.

\subsection{Encourages student-faculty contact}

For students who have little experience with undergraduate research projects, it is important to model that process and provide guidance throughout. Constructive student-faculty interaction allows for a meaningful mentoring process and shows students that the instructor is a partner in the research process. I begin my course with an assignment designed to open up channels of communication. Students are required to write a letter of introduction that is somewhat autobiographical. I ask them to boast about their accomplishments, tell me about their family, and explain why they chose to study economics, what courses they have taken and which was their favourite. I also ask them to describe what topic they would like to explore for their research and what they think will be the hardest part of completing the project. Finally, because I want them to be serious in response to these questions, I provide them with a required word count, no less than 1000 and no more than 1500 words. On the second day of class, I provide a similar letter written by myself to them. I have found that this simple act provides me with great insight into the very factors that are likely to inhibit or enhance their success in the project and it immediately allows me to talk with rather than at my students.

Throughout the semester other exercises and activities are designed to model the research process as typically collaborative, suggesting that they need to involve me in their research and not simply report it to me. For example, after the first week in the semester I share one of my 
current or recent projects bringing a large accordion folder of materials to class. I explain how I got started on the idea, show them the various outlines, false starts and other documents I used to get down to the important research question. I also make it a point to share with them a version of one of my papers that has been marked up significantly by a co-author as well as referee reports of submitted work. The importance of sharing this information cannot be overstated. Students see that we have the same struggles with research as they will have and it humanises us in their eyes. This reinforces the commonalties that are introduced using the letter of introduction and helps to build a community of scholars.

At critical times during the semester I require one-on-one meetings with each student, typically lasting up to 30 minutes. At the beginning of the semester these meetings are designed to encourage students to brainstorm potential project ideas. Later in the semester these meetings provide the opportunity to effectively gauge students' progress and provide them with reflective guidance; nurturing weaker students, pushing stronger ones to take their analysis to a new level. Because previous exercises have already opened up the lines of communication, these meetings are very productive.

\subsection{Encourages cooperation among students}

Building a community of scholars is a supportive way of nurturing students through their research. Students should be able to provide each other with support and constructive feedback as they conduct themselves through the undergraduate research process. Cooperative learning exercises can be designed for early steps of the project such as topic generation, constructing an effective economic research question and developing solutions for commonly confronted problems. Later in the project students should be required to provide peer feedback on draft versions of reports. This not only provides another set of reflective comments, it also demonstrates to the reviewer alternative ways to organise relevant literature or evidence and to develop an analytical story.

\subsection{Encourages students to undertake projects that have personal relevance and interest}

Students learn best when they are engaged with the subject material. Research projects that provide students with great latitude in developing their investigative question or that make the work they are doing personal provide the greatest opportunity to engage students. For example, in a labour economics course students can be asked to develop an analysis of labour force participation decisions using their own family members. In choosing a family member that they know less about (as opposed to their parents) students often discover work patterns and decisions of which they were completely ignorant, and they learn how to apply theoretical principles in the process. Typically, data are gathered through interviewing various family members and this in turn generates insights into alternative methods of evidence and data gathering techniques. For more information on such techniques, see Geertz (1973) and Van Maanen (1988).

\subsection{Provides constructive feedback}

Various steps within the research process necessitate differing degrees of feedback with respect to the level of detail and the speed at which it is provided. Prompt feedback is especially critical during the first steps of the research process as students struggle to define a narrow enough topic and develop an associated effective economic research question. In this part of the course, shorter assignments that allow in-class peer feedback and next-class instructor feedback are critical for keeping students on task and moving forward on their projects. As the semester 
progresses, requiring students to hand in components of their projects rather than waiting for a draft of the entire report ensures that instructors have the opportunity to provide prompt feedback and allows students the time to reflect on the changes necessary to enhance the report. This is especially important because most students consider research to be similar to answering an essay question - linear in nature. By requiring the intermediate evaluation of report components, students can be introduced to the iterative nature of research and receive guidance before they have wasted efforts moving too far down a path that is less productive. While one report section is under review, however, students can forge ahead on other sections of the project providing the instructor time to make the detailed types of comments that are necessary to nurture students through the research process.

As suggested elsewhere in this chapter, feedback mechanisms such as grading rubrics that students complete and hand in with their drafts allow them to critique their own work and help tutors to provide prompt critical reviews. These practices are likely to enhance student understanding of the evaluation process. Figure 5 provides one example of a grading rubric that is presented here as an assessment of the final paper. It could also be divided into relevant paper sections and used as a component of the interim evaluation. Students' self-assessment and peer reviews help to mitigate the workload falling on tutors.

\section{Figure 5 Grading Rubric for Final Paper}

Excellent Good Poor

\section{Outline}

\section{Abstract}

Introduction

Statement of topic and importance - defines your topic and provides insight for the reader as to the importance of your work. Comments:

Definition of concepts - includes a definition of relevant terms and organisations.

Comments:

Description of relationships - provides a basic introduction to the relationships across concepts that will be considered in your paper. Comments:

Statement of proposition - describes the hypotheses you will be investigating and your expectation as to the specific relationship expected. This should also provide a set up for your contribution section.

Comments:

Organisation of the paper - tells the reader what is to come and how you will tackle the problem you have set up.

Comments:

\section{Review of Literature}

\section{Introductory paragraph}

Provides transition into literature review from introduction section Introduces idea as one studied previously...in what ways... Introduces the literature review itself... alludes to presentation organisation.

Comments: 
Review presentation organisation

You need to have an organisation that makes sense such as chronologically or by topic.

Comments:

Articles included

(Thesis/main question, methodology, results, conclusions)

Relevant parts highlighted for link to your work

Clear understanding of article analysis and results.

Comments:

Summary/transition paragraph

Summarises literature succinctly

Provides a link to your project as a transition into the contribution section.

Comments:

\section{Contribution}

Provides a transition from literature review into contribution.

This typically begins with a statement of what will be demonstrated in your analysis.

Comments:

Provides a road map for the reader. In other words, it outlines sub-questions (components) that will be used to build evidence for hypothesis, relates them to the overall hypothesis and describes the process that will be used in presenting evidence.

Comments:

Evidence presented for each sub-question. This evidence must be clearly related to the sub-question and convincing to the reader.

Comments:

Summary of evidence in relation to the general hypothesis. This is the point at which you weigh all the evidence and determine whether it supports your hypothesis.

Comments:

Brief comparison of findings to previous research to the extent that this is relevant. May appear in different places throughout section.

Comments:

Effective use of tables, etc. (when applicable but note that even non-quantitative papers benefit from this form of evidence summation for the reader). This implies that tables can stand alone. Comments:

Caveats

Comments:

Conclusion

Excellent Good Poor

Brief description of your topic and hypothesis.

Comments:

Synthesised evidence for hypothesis.

Comments:

Research put into perspective - topic and beyond.

Comments: 
References (inclusion and format)

Mechanics

Organisation

Overall flow of ideas

Within paragraph flow

Sentence structure

Grammar, etc:

Spelling, grammar, punctuation and typos

Use/overuse of quotes

Audience

Appropriate level of language use and knowledge assumption

Professional and formal, rather than chatty and casual

Comments:

\subsection{Emphasises time on task (such as through strict timetables)}

Rarely do undergraduates fully comprehend the amount of time a quality research project will consume. Requiring a series of assignments linked to the steps of the research process and having firm deadlines throughout the semester encourages students to focus on the task at hand and remain on track rather than getting overwhelmed by the seeming enormity of the entire process. The use of in-class discussions and one-on-one meetings present an opportunity to reinforce the need for a dedicated effort. For courses in which the entire focus is the research project (such as the capstone course described in the case study accompanying this chapter), class time should only be used for group activities and discussion. More emphasis should be placed on the one-on-one meetings. Keeping students on task in courses that contain an undergraduate research component as an addition to course content can be more difficult as the focus of the class is primarily on topical material. In such cases, short student presentations designed to provide evidence of progress can be used to keep students on task and remind them of the next stages of the research process.

\subsection{Communicates high expectations}

Students need to understand that they are expected to produce a quality economic analysis that is effectively communicated. For example, describing previous student projects and emphasising students' existing skills can help them to believe that they have the potential to succeed. Providing examples such as the abstracts of projects completed in previous semesters can signal both appropriate topics and types of analysis that are acceptable. Figure 6 includes six examples of abstracts for undergraduate research projects completed as part of a senior capstone experience course. (More details about this course are provided in the first case study.) Students can be required to review the abstracts and identify why the project was acceptable for a senior thesis. A class discussion of the key components mentioned in the example abstracts sets expectations. 


\section{Figure 6 Communicating High Expectations: Models of Past Abstracts}

\section{Perceived Corruption and Foreign Investment: Are Investors Vigilant?}

Corruption has emerged as an important global issue and is viewed as detrimental to any economy. Research has demonstrated that perceived corruption is negatively correlated to foreign direct investment flows. However, no research has attempted to demonstrate causality. This paper examines how yearly changes in perceived corruption affect yearly changes in foreign direct investment. Postulating that a negative relationship exists for data based on yearly levels, and for data based on yearly changes, estimates are made using up to 277 countries over four years. The results support previous findings of a negative static perceived corruption/foreign direct investment relationship. Although results indicate a negative relationship for yearly changes as well, they are not statistically significant. Deficiencies in the perceived corruption data impede conclusive findings.

\section{Should They be Mine or Should They be Ours?}

The oyster grounds of the Chesapeake Bay constitute an incredibly important resource both economically and ecologically. Oysters provide a natural filtration system for the bay's water column as well as support local watermen and the bay's communities. However, rapid depletion of the oyster populations occurred partly due to a lack of any form of restrictions on harvesting. Property rights were necessarily assigned to the grounds so that incentives may be in place to preserve the precious oysters. Both public and private oyster grounds exist throughout the bay, sometimes even side-by-side. The current study uses oyster harvest data from both Maryland and Virginia to examine which property rights structure seems to benefit the long-term production, and subsequent higher harvests, of the Chesapeake's oysters. It is hypothesised that public grounds may be a better system for production based on harvest method restrictions, impacts of disease on private grounds, the social benefits to the historic waterman culture, as well as an observed increase in the use of hand tongs in Virginia. Analyses revealed that public grounds might in fact be a more productive system for the long-run cultivation and harvest of oysters.

\section{The Ryan White CARE Act: Understanding the Allocation of Title II Funds}

The Ryan White Comprehensive AIDS Resources Emergency (CARE) Act is due for reauthorisation and amendment in September 2005. In deciding which amendments should be passed, the most hotly debated issue is on how to allocate CARE Act funds. Some argue that current funds favour only the extreme cases, i.e. 'the sick and dying'; others argue that the funds favour political agendas. This paper studies how funds are currently allocated to help shed light on whether there is any favouring, or if funds truly do assist people living with AIDS (PLWA) as they were meant to. In order to test this, this study hypothesises that there is a relationship between the allocation of funds and the levels of sickness of the AIDS population. Through regression analysis of the allocation of Title II funds and proxies for the level of sickness, this paper determines that there is indeed a relationship between the two. This implies that funding decisions do in fact assist PLWA at varying levels of illness and probably are not as much influenced by favouritism as politicians claim. The findings of this paper can be used as a basis from which to understand the validity of the points of debate over the CARE Act's amendment.

\section{And Then There Were Four}

The following paper defines the competitive state of the accounting industry. Mergers throughout the past 20 years, along with the contraction of Arthur Andersen, have raised many questions about the level of competition between the Big Four accounting firms. The Sarbanes Oxley Act of 2002 mandated that a study be conducted by the General Accounting Office (GAO) in order to gauge the competitive nature of the Big Four. The GAO study was unable to link directly consolidation to increased fees. The following analysis defines the structure, behaviour and performance of the accounting industry and proves that the market is an oligopoly. This results from the presence of barriers to entry for smaller firms, no direct price competition, increased non-price competition and obvious inefficiencies due to rises in litigation among the Big Four. Each of these leads to the assumption that only four large firms will result in increased prices in the future. The study enables an analysis of policy recommendations that discuss the options faced by the SEC. The most logical decision revolves around a long-term plan involving the consolidation of smaller firms, combined with the government subsidising their global expansion. 
Is the Market for Baseball Players Really 'Insane?’ An Analysis of Pay and Performance in Major League Baseball

Soon after final-offer arbitration and free-agency contracts were introduced into Major League Baseball in the late 1980s, researchers found that salaries generally aligned with marginal revenue products. Now, with a market seemingly willing to pay ever-increasing salaries for players, this paper asks whether or not teams continue to pay salaries equivalent to marginal revenue product. Using publicly available data from the 2001-3 seasons, a two-equation model estimates the impact of characteristics of play (runs, ERA, strikeout-to-walk ratio and fielding percentages) on winning percentage, and then the impact of winning percentage on revenues. The results are then applied as a case study to the Oakland Athletics to test if salaries for a team are comparable to marginal products. The answer is complex; on average, young players and players with three to six years of experience are paid less than their marginal revenue product, while hitters with more than six years of experience earn salaries generally in line with their contribution and pitchers with more than six years of experience earn salaries that exceed their marginal products.

'Why Do Environmentalist Organisations Opt for Lobbying Over Direct Market Participation?' This paper analyses the tastes and preferences of several environmentalist organisations in regards to direct participation in the pollution permit markets. In particular, the analysis focuses on the costs and benefits of direct market participation and compares these findings with the actual practices of these organisations. Theoretical models indicate that the purchasing of pollution permits by those who are being harmed by the polluting entities represents a relatively efficient way of reducing the overall amount of pollution in some cases. However, such measures are not considered by individual consumers or consumers organised into significant groups. The majority of environmentalist organisations focus their resources not on direct participation in the market, but on lobbying legislators. A comparison is then drawn between the behaviours of these organisations and those choosing not to participate in the market for human organs. The findings in this paper reveal that this behavior is motivated by the efficiency with which these organisations can achieve their stated goals through lobbying.

High expectations presented at the beginning of the semester need to be reinforced throughout the course. One of the advantages of the research project is that it can be an effective way to help students to develop independent learning. The revise and resubmission process (described in various places throughout this chapter) models this expectation as the instructor first points out deficiencies in communication and content and provides some examples of potential solutions, and in later stages merely points out such problems encouraging students to take responsibility. With respect to one-on-one meetings, a particularly effective method includes providing the students with a homework assignment as their ticket into the meeting, requiring them to complete a significant task specific to their research project on their own prior to the meeting.

\subsection{Respects diverse talents and ways of learning}

Students charged with completing an undergraduate research project come into that endeavour with very different backgrounds. Furthermore, they are likely to aim to acquire different skills throughout their studies insofar as they have diverse plans for employment and study after their degree. These differences suggest that although the research process should be consistently structured, the actual format of the project might be tailored to students' needs. This could be done by providing a number of alternatives such as:

- analysis using a historical perspective,

- focusing on contemporary economic issues,

- comparing alternative viewpoints in economics, and

- developing community-based projects.

Students are likely to be less familiar with these alternative formats than traditional empirical analysis and it is important to provide models and guidance throughout the process. 


\section{Evaluating Student Projects}

The most common form of evaluation is summative, used to judge performance and provide grades. In addition, formative evaluation can be used to support students' learning. Most evaluation instruments such as quizzes and examinations are summative whereas active learning techniques such as experiments and cooperative learning tend to be formative. The remainder of this section will highlight some key points to consider in developing criteria and processes for three dimensions of evaluation. It is critical that instructors develop formative and summative evaluation practices at three levels:

- research skills,

- economic analysis skills, and

- communication skills.

\subsection{Research skills}

The advantage of grounding the research project in a learning taxonomy (such as Hansen's proficiencies) is that it explicitly identifies the research skills we want our students to develop. Consider, for example, a research project that is designed so that students create new knowledge. This requires that students use their research skills to understand a body of literature, choose a topic and then develop an effective economic research question. The summative part of the evaluation process would include a measure of the students' success in demonstrating that they have a command of the foundational knowledge that supports such a question and the extent to which they could justify it in terms of the components - problemoriented, analytical, interesting and significant, amenable to economic analysis and feasible (Greenlaw, 2006: 14-18) - required for the question to be effective. But it is also critical at this juncture to provide constructive feedback (formative evaluation) to the student as they simply cannot continue until their research question is viable. Similar arguments can be made for other research skills that would be expected of a student for a project that is intended to have them create new knowledge including: locating key literature relating to this question, properly identifying an area of contribution, developing economic evidence in support of their hypothesis, and contextualising the results of their work.

\subsection{Economic analysis}

Developing structured arguments using economic analysis is one of the hardest tasks that students face in the research process. Detailed descriptions of project components can communicate the form and quality of economic analysis that is expected in a research project However, even when students are generally competent in summarising and synthesising literature, striking out on their own to conduct original analysis is completely foreign to them. This is one instance in which the process by which professionals conduct their own research is a natural model for students. Rarely does a professional paper become published that is not subject to review and revision. Often the revision entails strengthening the economic analysis and arguments: exactly what we want for our students. Challenging student arguments, offering alternative perspectives and correcting inaccuracies are critical inputs into the research process. It is important, however, to make sure that a student learns from this process and does not 
simply wait for feedback and revise the work accordingly. Feedback on multiple stages of a project can begin by providing nurturing comments in early assignments that signal expectations and provide editorial comments designed to show students how to improve their analysis. As the project progresses, however, these comments should simply point out problems and allow the student to develop the solution.

Special consideration needs to be given to the extent to which students are expected to create new knowledge. Undergraduate research projects have great potential to push students beyond the boundaries of their current knowledge in a variety of ways. The use of undergraduate research as a pedagogical tool is all about stretching students' minds and providing them with skills to act like economists. A word of caution is appropriate, however, since the structure of undergraduate research projects closely mimic professionally developed publications; it is tempting to develop too high expectations for students. To avoid unnecessary frustrations it is important that new knowledge creation be judged in the context of the students' knowledge base and demonstrate the achievement of the proficiencies rather than using our professional knowledge base as the benchmark.

\subsection{Communication skills}

As suggested above, presentation matters in the case of undergraduate research more than in most other learning exercises. Student learning as a result of the research process is more sophisticated and it requires a complementary level of communication, either oral or written.

In the case of oral skills one can model expectations and provide formative feedback through class discussions regarding specific components of the research process. For example, students can be asked to provide an oral justification of their research question to a small group of classmates. This provides a good opportunity for students to practise formulating their thoughts in a public forum and to receive constructive feedback that will improve their question (and subsequent research project). Oral communication skills can also be evaluated during one-onone meetings. Since students must explain the status of their project and their future plans, the tutor can observe communication skills in an informal setting and provide guidance on how such skills may be improved. Summative evaluation can be achieved through presentations to peers and academics.

Research (Lehr, 1995) suggests that an understanding of the revision process is a key component for developing and improving writing. Writing skills can be enhanced when students are required to develop sections of their projects through revision and resubmission. This is likely to help students to improve their arguments and it is also likely to help with two key components with which students often struggle: organisation and grammar. As with the process described for economic analysis, feedback on students' written communication should progress from nurturing and providing examples of solutions to the point at which they simply point out errors and require the student to develop the necessary revisions. Once again, the one-on-one meetings can help this process because they provides a more collaborative forum for discussing recurrent problems and encourages students to see the value in this formative evaluation of their work and the opportunities that the revision process provides.

Other helpful processes that encourage good writing include the use of grading rubrics and model writing. Signaling expectations through the use of grading rubrics that include sections for both content and communication skill evaluation encourage students to take the communication of content more seriously, especially if they are also required to evaluate their own work using the rubric. While presenting models of good student writing from previous semesters might also help students understand expectation levels, it can provide some students with a crutch leading to papers that are mirror images of the models. A more effective way to use sample writing as a model is to provide a single first draft paragraph along with the multiple revisions that demonstrate the development into a much-improved final version. 
In summary, it is important to recognise and provide opportunities for summative and formative methods of evaluation that can occur formally via written evaluations of work and informally during class exercises and one-on-one meetings.

\subsection{Getting Students to Evaluate the Quality of their Own Work}

How do we get our students to recognise the quality of their own work? My experience suggests that we need to provide guides and models that students can use as indicators of quality. Such guides should run the gamut from general to specific. For example, three handouts I have used to help my students develop a better understanding of what it means to do quality research include:

- grading scale models

- a guide of writing tips based on common errors

- peer/self review guides.

Students are less likely to have accurate understanding of tutors' definitions of top-quality work if these definitions are not disclosed to them. The course guide I provide all my research students with is over 100 pages and contains descriptions of expectations, research and writing tips, course assignments and evaluations (to be completed by the student, peers and the instructor). The guide aims to:

- signal that this is a serious endeavour;

- provide a clear structure for students' work; and

- highlight the multiple components of the research process.

One of the very first documents in this guide is a grading scale that specifically identifies what it takes to earn an A, B, C, D or F. Each grade is described in terms of what the written report includes, what it does not include and the way that information should be communicated. There are many such grading scale models available from which one might develop a specific guide for students. See for example:

- http://cte.rockhurst.edu/FileUploads/short_guide_to_grading.pdf,

- http://mockingbird.creighton.edu/worldlit/program/grading-essays.htm and

- http://www.hist.umn.edu/ bywelke/Formal\%20Paper\%20Grading\%20Guide.htm.

Since mistakes made by novice researchers tend to be consistent over time, I provide my students with a series of research tips before they even begin their research projects (Figure 7). These tips focus on the research process as well as the expected output. More importantly, the class discussion that accompanies this handout is focused on why these items are important.

\section{Figure 7 Research Tips for Students}

While many of these statements are specific to the final research product, now is a good time to get an idea of my expectations and problems to avoid.

1. Keep track of your research. The semester is short and we have a lot to do. It is in your best interest to keep detailed notes as to the research you have completed, both the process you have used and the results you have found. Don't make the mistake of having to look for a source or a page of a citation at the last minute. If you look ahead in the course schedule you will notice that this will be facilitated through the creation of a research binder that will be turned in at various points during the semester. 
2. Thesis statements. Written assignments must have a thesis, a single major point. A thesis is a guide for the reader, one that tells your audience the purpose of your essay. It is a statement that encourages the reader to continue. Thus, it should be explicitly stated at the onset of your work. The reader should not have to search for your thesis statement. Good thesis statements often answer the questions 'How?' and/or 'Why?'

3. Your title. This is one place to show your creativity. A title grabs the attention of the reader, makes them want to read your work, and provides information as to the content of the paper.

4. Organisation. Written work should be organised around a purpose. The beginning should tell the reader what it is you are trying to accomplish in your work. The middle should begin with the background (often in the form of a review of literature) needed to set up the question you are addressing followed by the evidence or arguments used to support your thesis. This should then be followed by a conclusion (more below).

5. Know your audience. Recognise that the readers for most of your written work are your peers in class as well as Dr. M. You should assume a general familiarity with economic terms, but be sure to include explanations of less commonly known concepts. Do not use jargon or terms not generally familiar to the reader.

6. Introduction. Don't start with an introduction that is too far reaching or is narrative in format. You are trying to motivate the reader to continue. Introduce the specific issues you will be addressing in your paper in a way that is interesting.

7. Answering your economic question. It is critical that in the body of the paper you actually address the thesis you put forth in your introduction. This requires detailed evidence in support of your ultimate answer. Do not simply link a bunch of quotes together and assume the reader understands the link to your thesis. Be specific and explicit in your linking of evidence to the economic question. In addition, avoid unsupported statements or ones that are clearly supported only by opinion. Hint: a paper with a lot of quotes implies that you did not understand the evidence enough to put it into your own words. This also suggests that you are unlikely to convince the reader. In her book, Economical Writing, McCloskey notes that: 'Writing is Thinking' (p. 6). Bad writing implies poorly thought-out ideas. If you do not understand the content of your arguments, it will surely be reflected in your writing.

8. Make a Persuasive Argument. “... evidence should be accurate, authoritative, precise, clearly explained, complete and representative.” Greenlaw Ch 4, p.8.

9. Avoid Logical Fallacies. Greenlaw Ch 4, Appendix.

10. Tangents. Don't go off on tangents. Be sure that the evidence you include in your paper directly addresses your economic question. Keep asking yourself what evidence this contributes to support the ultimate conclusion.

11. Take us along for the ride. Don't assume the reader knows where you are going with your arguments. Make the path easy for them to follow. The key to this is to include well-formulated paragraphs in your essay. Each paragraph should develop a specific idea, and the first sentence or two of a paragraph should provide a transition from the previous paragraph and announce what is coming in the current paragraph. The content of the paragraph should then be directly related to what is announced in the first one or two sentences. Hint: read each paragraph and come up with a couple of words to describe their content. Place these words alongside your paragraphs in the margins. Then review the work by reading these summaries from start to finish. Do they flow? (They should if your outline was well formed.)

12. The conclusion. Don't just rehash the introduction. The conclusion is where you need to wrap it all up. You want to make that final push to convince the reader that you have answered the economic question you proposed in your thesis. One way to accomplish this is to put the work you have completed in a broader context that shows its importance. In other words, make sure the conclusion follows from the evidence. Greenlaw Ch 4, pp. 3-5 
13. First person. Although writing in the fist person is not incorrect, it is best avoided. Using the first person often leads to subjective and imprecise statements. Writing in economics is a formal process and this project requires evidence in answering an economic question. Thus, your project should not be written using the first person.

14. Format. Your final paper must be typed, double-spaced and include a list of references (at the end of the paper, not as footnotes). The paper should be standard 12 pitch font, New Times Roman with one-inch margins on all sides. Do not justify the right margin. Draft papers and sections must be stapled in the upper-left corner. Final papers must be spiral bound. A title page must include the title of your paper, your name, the date, the course title and the complete pledge must be written in full and signed. To avoid interruption of the flow of your written work, all tables, graphs and charts should appear after the text but prior to the references page. Be sure that each table has the appropriate degree of self-explanation (can it stand alone, independent of the text?) and is appropriately labelled for text reference.

15. References. Remember to include only those sources actually cited in the paper. These are to be listed in alphabetical order at the end of the paper. Make sure to document all sources, direct quotations, paraphrases and any information that is not your own. Be especially careful about plagiarism, see the course syllabus for more information. When in doubt, cite it!

16. Computer problems. This will not be an excuse for late work. Do not wait until the last moment to complete or print out your work. Back up your research often, including sending an email copy to yourself!

17. Writing Centre. Good writing is a form of communication. Your ideas will get lost if the reader keeps getting lost because of a lack of organisation or poor grammar. The writing centre staff are there to help you improve your written communication skills. Even good writers can benefit from this service. For more information visit http://writing.richmond.edu/.

18. The Writer's Web is an especially useful source of helpful hints and guidelines for writing at various stages of the process. I encourage you to review this resource before you begin your work! http://writing2.richmond.edu/writing/wweb.html.

References:

Greenlaw, S. (2006) Research Methodology: A Guide for Undergraduate Economic Research, Houghton-Mifflin.

McCloskey, D. (2000) Economical Writing, 2nd edition, Waveland Press, Inc.

Finally, because students (not unlike ourselves) find it easier to be critical of another person's work rather than see similar flaws in their own work, I implement a peer review process of all final drafts of research projects. The peer review document in Figure 8 has a combination of general and specific questions relating to both the content and presentation of the economic analysis. Not only does this review provide students with a new set of comments on their papers, but often reading another student's paper provides another model for organising arguments, shows examples of common mistakes that are made, and stresses the importance of clear and concise communication. After students have reviewed a peer's work, I ask them to reread their own work (prior to receiving the peer comments). They are asked to identify (in much the same manner as they did in reviewing their peers' work) the strengths and weaknesses of their own research. Because the process of reviewing is fresh in their minds, they are more likely to be critical of their own research. 


\section{Figure 7 Peer Review of Paper Draft}

\section{Title of Paper:}

Directions: Answer the following questions thoughtfully, clearly and concisely. Use complete sentences and specific examples (or page references) to make your advice as understandable as possible. You will be evaluated on the thoroughness and helpfulness of your responses to your peer partner. To make your review as beneficial as possible, it is important that you follow the review steps in the order given below:

First, read the paper carefully, without pausing to comment, to get the overall effect of the paper.

In the space below, write down your general feelings about the paper. Is it interesting? Did it generally maintain your interest? Is it easy to follow (organisation is clear)? Did you get lost along the way?

Next, look over all the questions below and then reread each section of the paper and answer the related questions. As you reread the paper make margin notes to the author identifying which paragraphs/sections were clear and which ones were not.

Title and Introduction: The introduction should present the topic and its importance. It should clearly define relevant concepts, provide an overview of relationships, present the thesis and indicate how it will be developed, and generally prepare the reader for the paper to follow.

1. Does the title reflect the content of the paper? Is it interesting?

2. Are the relevant concepts defined? Make a list of the concepts introduced and note which ones are not clearly defined.

3. Are the relevant relationships described? Make a list of the relationships that were introduced and note which ones were not clearly described.

4. Is the economic question clearly presented? What is the paper's thesis or main argument? Describe this in your own words in the space below and identify it in the paper using a margin note. (Provide the page number on which this appears.)

5. Did the introduction adequately convey the importance of this topic? Why or why not?

6. Rating: On a scale of 1 to 5 ( 5 being excellent) what rating would you give this introduction? Explain.

Review of Literature: The review is designed to inform the reader of what other work has been completed on this topic and to motivate the current work. The review presentation should be organised (such as chronologically or by theme) and be directly related to the research project.

1. Does the depth of review provide enough background to understand the nature of previous studies? Explain.

2. Is the review sufficiently linked to the current project? Identify links in the paper using margin notes and provide the page numbers where these appear.

3. Rating: On a scale of 1 to 5 ( 5 being excellent) what rating would you give this review section? Explain.

The Contribution Section: In reviewing this section you should mark each sub-section as excellent if it can be clearly identified in the paper, if it accomplishes what is expected, if you are not left with any content questions, and if it is well written (good flow between and within paragraphs, good sentence structure, etc.). Poor sub-sections are those that are not clear because of incoherent content or flow issues, are incomplete leaving you with unanswered questions or issues not sufficiently addressed, or missing altogether. 
Please be sure to provide comments for each subsection!

Contribution Section

Statement of what will be demonstrated in the analysis

Comments:

Set up of relationships

Comments:

Hypothesis development

Comments:

Description of method

Comments:

Evidence

Comments:

Relation of evidence to general hypothesis

Comments:

Comparison of findings to previous research

Comments:

Effective use of tables, etc. (where applicable)

Comments:

Rating: On a scale of 1 to 5 (5 being excellent) what rating would you give this contribution section? Explain.

Conclusion: A conclusion must go beyond a simple restatement of the overall argument of the paper. It should provide a final push to convince the reader that the economic question proposed in the thesis has been answered.

1. Is a short reiteration of the topic and hypothesis presented? Identify this in the paper by using a margin note and note on which page this appears.

2. Is the evidence synthesised sufficiently that you are convinced of the answer to the economic question? Explain.

3. Is the research contextualised in a broader economic issue that indicates its importance? State this broader issue.

4. Rating: On a scale of 1 to 5 ( 5 being excellent) what rating would you give this conclusion section? Explain.

Readability: A research paper can only effectively convey its message if it is well written.

1. Was the paper clearly written? Highlight or make margin notes for any paragraph or section that you had to reread to understand or still were not sure what the contribution of the section was to the overall paper. (Note these section pages below.) Explain to the author what was not clear and any questions that you still have.

2. Is the language use appropriate? And the audience accurately gauged?

3. Does the paper suffer from grammar or organisational problems that inhibit the message of the author?

Grammar: yes, very distracting yes, somewhat distracting no

Organisation: yes, very distracting yes, somewhat distracting no

4. Rating: On a scale of 1 to 5 ( 5 being excellent) what rating would you give for readibility? Explain.

Final thoughts:

1. What is the main strength of this paper?

2. What is one weakness of this paper?

3. What was the single most important contribution of this paper?

4. Rating: On a scale of 1 to 5 ( 5 being excellent) what rating would you give the paper overall? Explain. 


\section{References and further reading}

\section{Articles Describing Examples of Student Research Projects in Economics}

Elliott, C. (2004) A May American Economic Review Papers Seminar and an Analytic Project for Advanced Undergraduates, Journal of Economic Education, Vol. 35 (3), p. 232-242.

Elliott, D., Meisel, J. and Richards, W. (1998) 'The Senior Project: Using the Literature of Distinguished Economists', Journal of Economic Education, Vol. 29 (4), p. 312-320.

McElroy, J. L. (1997) 'The Mentor Demonstration Model: Writing with Students in the Senior Economics Seminar', Journal of Economic Education, Vol. 28 (1), p. 31-35.

Simpson, M. S. and Carroll, S.E. (1999) 'Assignments for a Writing-Intensive Economics Course', Journal of Economic Education, Vol. 30 (4), p. 402-410.

\section{Textbook for Undergraduate Students in Economics Embarking on Research}

Greenlaw, S. A. (2006) Doing Economics: A Guide to Understanding and Carrying Out Economic Research, Boston: Houghton Mifflin Company.

\section{Undergraduate Research Journals: Economics \\ Undergraduate Economics Review http://titan.iwu.edu/\%7Eecon/uer/}

The UER is a peer-reviewed journal aimed at promoting high-quality undergraduate research. It is supported by the Department of Economics at Illinois Wesleyan University. If you wish to promote the UER on your campus, a promotional flyer is available for distribution. Also, please note that this website is still under construction and will be updated frequently.

Issues in Political Economy: Undergraduate Student Research in Economics http://org.elon.edu/ipe/

Issues in Political Economy is committed to supporting and encouraging quality undergraduate research in all areas of economics. Now in its 14th volume, the journal was founded on the belief that the best way to learn economics is to do economics. Through the process of research, writing and peer review, students actively engage the discipline in a way not possible by simply listening to lectures and reading textbooks. In short, undergraduate research is a vital component in an economics education. The literature suggests that students take projects more seriously and learn more when the project is directed towards an external rather than an internal audience such as a class assignment. IPE is designed to provide an external audience for such research.

\section{Undergraduate Research Journals, Other Disciplines and Interdisciplinary}

Council on Undergraduate Research: http://www.cur.org/ugjournal.html

The Undergraduate Journals and Conferences Directory : http://upd.mercyhurst.edu/ 


\section{Conferences for Undergraduate Students Conducting Research}

National Conferences on Undergraduate Research http://www.ncur.org/

\section{Economics Research Cited}

Becker, W. E. and Watts, M. (1996) 'Chalk and Talk: A National Survey on Teaching Undergraduate Economics', American Economic Review. Vol. 86 (2). pp. 448-53.

Berik, G. (1997) 'The Need for Crossing the Method Boundaries in Economics Research', Feminist Economics, Vol. 3(2), pp. 121-125.

'Best Practices in Undergraduate Research'. Panel discussion at the 2006 Southern Economic Association meetings. Participants included Steven Greenlaw (University of Mary Washington), Jessica Holmes (Middlebury College), KimMarie McGoldrick (University of Richmond), John Siegfried (Vanderbilt University) and Dennis Sullivan (Miami University of Ohio).

Colander, D. and Holmes, J. (2006) 'A Capstone Course in Economics: To What, and For Whom?' in Colander, D. The Stories Economists Tell: Essays on the Art of Teaching

Economics, New York: McGrawHill Irwin, pp. 71-78.

Hansen, W. L. (1986) 'What Knowledge Is Most Worth Knowing For Economics Majors?', American Economic Review, Vol. 76 (2), pp. 149-152.

Hansen, W. L. (1993) 'Teaching a "Writing Intensive” Course in Economics: An Assessment', Journal of Economic Education, Vol. 24 (3), pp. 213-218.

Hansen, W. L. (1998) 'Integrating the Practice of Writing into Economics Instruction', in W.E. Becker and M. Watts (eds), Teaching Economics to Undergraduates: Alternatives to Chalk and Talk, Cheltenham, UK and Northampton, Mass.: Edward Elgar, pp. 79-118.

Hansen, W. L. (2001) 'Expected Proficiencies for Undergraduate Economics Majors', Journal of Economic Education, Vol. 32 (3), pp. 231-242.

Hansen, W. L. (2004) 'A Proficiency-Based Economics Major: Its Architecture and Artistry'. Paper presented at the Midwest Conference on Student Learning, University of Akron, Ohio, 5 November 2004.

Hansen, W. L. (2005) 'Designing and Implementing "Proficiency-Based" Economics Courses', paper presented at the Midwest Economics Association Meeting, March 2005.

Hansen, W. L. (2006) 'Proficiency-Based Economics Course Examinations'. Paper presented at the Midwest Economics Association Meeting, March 2006.

McGoldrick, KM. (1998) 'Service-Learning in Economics: A Detailed Application', Journal of Economic Education, Vol. 29 (4), pp. 365-376.

McGoldrick, KM. (2006) 'The Senior Experience for Economics Majors: Results from a Survey of Departmental Practices'. Presented at the American Economic Association meetings, January 2006.

McGoldrick, KM. (Under review) 'Applying the Tools They Have Mastered: The Senior Research Course in Economics.'

McGoldrick, KM. and Ziegert, A. (eds) (2002) Putting the Invisible Hand to Work: Concepts and Models of Service Learning in Economics, Ann Arbor: The University of Michigan Press.

Russell, S. (2005) 'Illuminating Cases: Understanding the Economic Burden of Illness through Case Study Household Research', Health Policy and Planning, Vol. 20(5), pp. 277-289 
Santos, J. and Lavin. A. M. (2004) 'Do as I Do, Not as I Say: Assessing Outcomes When Students Think Like Economists', Journal of Economic Education, Vol. 35(2), pp.148-161.

Siegfried, J. J. (2001) 'Principles for a Successful Undergraduate Economics Honors Program', Journal of Economic Education, Vol. 32(2), pp. 169-177.

Siegfried, J., Bartlett, R. L., Hansen, W. L., Kelley, A. C., McCloskey, D. N. and Tietenberg, T. H. (1991) 'The Status and Prospects of the Economics Major', Journal of Economic Education, Vol. 22(3), pp. 197-224.

Siegfried, J. J. and Wilkinson. J.T. (1982) 'The Economics Curriculum in the United States: 1980', American Economic Review, Vol. 72(2), pp. 125-138.

Simpson, M.S. and Carroll, S.E. (1999) 'Assignments for a Writing-Intensive Economics Course', Journal of Economic Education, Vol. 30 (4), pp. 402-410

\section{General Education and Other Disciplinary Research Cited}

Adhikari, A. and Nolan, D. (2002) 'But What Good Came of It at Last? How to Assess the Value of Undergraduate Research', Notices of the AMS (American Mathematical Society), Vol. 49(10), pp. 1252-1257. http://www.ams.org/notices/200210/comm-nolan.pdf

Baxter Magolda, M. B. (2001) 'A Constructivist Revision of the Measure of Epistemological Reflection', Journal of College Student Development, Vol. 42(6), pp. 1-15. http://unixgen1.mcs.muohio.edu/ magoldpm/PDF/MER_OVERVIEW.PDF

Boyer, E. L. (1990) Scholarship Reconsidered: Priorities for the Professoriate, San Francisco: Jossey-Bass.

Boyer, E. L. (1997) 'A Community of Scholars'. The Emory Symposium, Atlanta, Georgia, 14 April 1994, in Selected Speeches, 1979-1995, San Francisco: Jossey-Bass, pp. 69-80.

Boyer Commission Reinventing Undergraduate Education: A Blueprint for US Universities. (1998) http://naples.cc.sunysb.edu/Pres/boyer.nsf/.

Chickering, A. and Ehrmann, S.C. (1996) 'Implementing the Seven Principles: Technology as Lever', AAHE Bulletin, October, pp. 3-6.

Chickering, A. and Gamson, Z.F. (1991) 'Applying the Seven Principles for Good Practice in Undergraduate Education', New Directions for Teaching and Learning, No. 47, pp. 1-3, San Francisco: Jossey-Bass Inc.

Gamson, Z. (1991) 'A Brief History of the Seven Principles for Good Practice in Undergraduate Education', New Directions for Teaching and Learning, No. 47, pp. 5-12, San Francisco: Jossey-Bass Inc.

Geertz, C. (1973) The Interpretation of Cultures, New York: Basic Books.

Graham, C., Kursat C., Byung-Ro L., Craner, J. and Duffy, T. M. (2001) 'Seven Principles of Effective Teaching: A Practical Lens for Evaluating Online Courses', The Technology Source. Available online at http://horizon.unc.edu/TS/default.asp? show=article\&id=839.

Hake, R.R. (1998) 'Interactive Engagement v. Traditional Methods: A Six-Thousand-Student Survey of Mechanics Test Data for Introductory Physics Courses', American Journal of Physics, Vol. 66, pp. 64-74.

Hathaway, R.S. et al. (2002) 'The Relationship of Undergraduate Research Participation to Graduate and Professional Education Pursuit: An Empirical Study', Journal of College Student Development, Vol. 43(5), pp. 614-631. 
Hakim, T. M. (2000) 'How to develop and administer institutional undergraduate research programs', Washington, DC: Council on Undergraduate Research.

Hess, G. F. (1999) 'Seven Principles for Good Practice in Legal Education: History and Overview', Journal of Legal Education, Vol. 49(3), pp.367-370.

Jenkins, A. (2004) 'Designing a curriculum that values a research-based approach to student learning', Link 9, pp. 1-4. http://www.hlst.heacademy.ac.uk/resources/link9/link9.pdf.

Kardash, C. M. (2000) 'Evaluation of an Undergraduate Research Experience: Perceptions of Undergraduate Interns and their Faculty Mentors', Journal of Educational Psychology, Vol. 92(1), pp. 191-201.

Lehr, F. (1995) 'Revision in the Writing Process', Eric Digests online, ED\#379664 http://www.eric.ed.gov/ERICDocs/data/ericdocs2/content_storage_01/0000000b/80/2a/22/78.p df.

Lopatto, D. (2003) 'The Essentials of Undergraduate Research', Council on Undergraduate Research Quarterly, March, pp. 139-142

Lopatto, D. (2006) 'Undergraduate Research as a Catalyst for Liberal Learning', Peer Review, Vol. 8(1), pp. 22-25.

Merkel, C. A. (2003) 'Undergraduate Research at the Research Universities', New Directions for Teaching and Learning, Vol. 93, pp. 39-54, San Francisco: Jossey-Bass, Inc.

Nagda, B.A., Gregerman, S.R., Jonides, J., von Hippel, W. and Lerner, J.S. (1998)

'Undergraduate Student-Faculty Research Partnerships Affect Student Retention', The Review of Higher Education, Vol. 22 (1), pp. 55-72.

http://www.undergraduate.research.umich.edu/homeassessment.html

New Directions for Teaching and Learning (2003) Special Issue: Valuing and Supporting Undergraduate Research, Vol. 93, pp.1-92.

Prince, M. (2004) 'Does Active Learning Work? A Review of the Research', Journal of Engineering Education, Vol. 93(3), pp. 223-231.

Rueckert, L. (2002) 'Assessment of Research', CUR Quarterly, Sept., pp. 10-11.

Sorcinelli, M. D. (1991) 'Research Findings on the Seven Principles', New Directions for Teaching and Learning, Vol. 47, pp. 13-25, San Francisco: Jossey-Bass, Inc.

Ward, C., Bennett, J.S. and Bauer, K. (2003) 'Content Analysis of Undergraduate Research Student Evaluations', unpublished report. http://www.udel.edu/RAIRE/Content.pdf

Van Maanen, J. (1988) Tales of the Field: On Writing Ethnography, Chicago: University of Chicago Press.

\section{Websites}

Council on Undergraduate Research: Learning Through Research

http://www.cur.org/about.html

'The Council on Undergraduate Research (CUR) and its affiliated colleges, universities, and individuals share a focus on providing undergraduate research opportunities for faculty and students at predominantly undergraduate institutions. CUR believes that faculty members enhance their teaching and contribution to society by remaining active in research and by involving undergraduates in research. CUR's leadership works with agencies and foundations to enhance research opportunities for faculty and students. CUR provides support for faculty development. Our publications and outreach activities are designed to share successful models and strategies for establishing and institutionalizing undergraduate research programs. We assist 
administrators and faculty members in improving and assessing the research environment at their institutions. CUR also provides information on the importance of undergraduate research to state legislatures, private foundations, government agencies, and the U.S. Congress. CUR welcomes faculty and administrators from all academic institutions. Our primary advocacy is in support of faculty and students at predominantly undergraduate institutions. CUR achieves its vision through efforts of its membership as organized in a divisional structure that includes biology, chemistry, geosciences, mathematics and computer science, physics and astronomy, psychology, social sciences, an at-large division that serves administrators and other disciplines, and a division for directors of undergraduate research programs.'

\section{The Higher Education Academy}

http://www.heacademy.ac.uk/default.htm:

'The Academy's mission is to help institutions, discipline groups and all staff to provide the best possible learning experience for their students.

Strategic aims and objectives are:

- To be an authoritative and independent voice on policies that influence student learning experiences

- To support institutions in their strategies for improving the student learning experience

- To lead, support and inform the professional development and recognition of staff in higher education

- To promote good practice in all aspects of support for the student learning experience

- To lead the development of research and evaluation to improve the quality of the student learning experience

- To be a responsive, efficient and accountable organisation.'

The Reinvention Centre: A Centre for Excellence in Teaching and Learning http://www2.warwick.ac.uk/fac/soc/sociology/research/cetl/ugresearch/

'The Reinvention Centre for Undergraduate Research aims to integrate research-based learning into the undergraduate curriculum. The purpose is not simply to teach undergraduates research skills but to enable undergraduates to become integrated into the research cultures of their departments.' Website includes the key resources on programmes, funding, projects and reading references.

\section{The USYD Project}

http://www.itl.usyd.edu.au/RLT/usydproject/about.htm

'The aim of this initiative is to enhance students' learning experiences by progressing the ways in which undergraduate teaching is informed by research at all levels in the University of Sydney. It furthers the University's strategic objectives to provide curricula informed by research, scholarship and creative works and professional practice; to employ staff with a commitment to teaching informed by research; to assist the transition of students into research-based programs through opportunities provided within undergraduate staff programs to support the conduct of outstanding research by both staff and students.' 


\section{Case Study: The Capstone Experience in Economics Course: An Application of Undergraduate Research in a Class Dedicated to the Research Process}

\section{Summary}

'Capstones' are culminating experiences situated in the final year of an undergraduate students college curriculum and are designed around students demonstrating mastery of both content and application of relevant subject matter. In economics, these are often in the form of a cumulative (written and/or oral) examination, senior seminar or research course. Senior seminar classes typically focus on a single field of economics and expose students to primary source articles in a small class setting and require students to practise their analytical thinking in greater depth than other elective courses. Often these courses require students to complete research associated with a topic and present the results of their work. Courses that are dedicated to research are designed to have students apply the tools they have learned throughout their major to a particular research issue. This differs from the seminar in that the project is a greater component (or even the entire focus) of the course and the choice of issue to be explored is less restricted. This case study describes one such research course including the development and structure of the course, course project format options, a sample of student topics and associated investigative questions developed, some practical advice on planning and scheduling, and finally a note about evaluation. A review of the chapter prior to reading this case study will provide the reader with additional context for the descriptions provided.

\section{Development and structure of the course}

The Capstone Experience in Economics course described herein was developed because my economics department wanted students to have a culminating experience at the end of the major in which they demonstrated mastery of skills associated with the major, such as described by Hansen's proficiencies (see section 4 and Figure 4 of this chapter). The course was constructed in a manner that is consistent with the description of undergraduate research as presented in the accompanying chapter. As developer of this course, I felt that students would gain even more in terms of skill development if their experience was grounded in their own interests as opposed to a prescribed set of topics. As a result, no topic-driven content was covered during the course; rather, the students investigated an issue and the course focused on the development of analytical thinking and research skills. Although no explicit links to other courses were presented during the class itself, students were constantly challenged to integrate their research with what they had learned in other courses taken as part of their major.

The course developed for this experience has four stages:

1. Determining a research focus: The goal of this section of the course is to nurture students through the process of narrowing their topic, developing an effective economic research question and constructing a plan for their research. Students begin the semester with assigned readings that model the various forms of research and the types of evidence used by social scientists. During regularly scheduled classes the students learn about the research process through cooperative group exercises that deconstruct articles, identifying the economic question and outlining the process used to address the question presented. Out-of-class assignments require each student to apply these skills in the development of their own project.

2. Beginning analysis: By this stage students have narrowed their issue to a specific economic question and searched relevant literature for areas of potential contribution. Class meetings become less frequent and are typically focused on groups of students doing similar projects. For example, all students developing evidence that is quantitative in nature are required to attend a 
series of classes that refine their quantitative skills. Students bring their data to the computer lab and start the data analysis process. Since all students completing quantitative papers are required to begin their evidence sections with a thorough description of their data, including descriptive statistics, this in-class process is efficient from both the student and the instructor point of view. Students learn from each other as they work through the initial stages of data analysis and common problems that arise are addressed in a single forum.

3. Evaluating evidence: The final stage of the course is dominated by one-on-one meetings with the instructor with few class meetings. By the time the students are deep into the development of their evidence their questions become project specific. It is more advantageous for students to use class time to work on their projects and meet individually with the instructor as issues arise. One-on-one meetings require that students complete some component of their analysis and bring specific questions to motivate the discussion. Many students have never experienced this degree of independent thought because throughout their education they have been told exactly what they should be learning, namely the presented course content. It is in this section of the course that the students who simply want the instructor to tell them what to do next are nurtured to the point of independent thinking. So that the students understand the importance of this process I typically use the analogy that their employer is not likely to tell them how to do something as much as to do something and report back with the results.

4. Bringing it all together: The first three section of this course require students to develop their projects in stages and they receive evaluative (formative and summative) feedback accordingly. This final section of the course provides students with the opportunity to synthesise the components of their projects and receive a final set of reflective comments, from their peers. (For more information about these forms of evaluation and feedback, see section 6 of the chapter.)

\section{Course project format options}

Students vary in their readiness to undertake a research project and the interests they have developed as a result of courses taken. To accommodate this variation they are provided with four descriptions of project options:

- Contemporary Economic Analysis: In a typical semester approximately half of the students choose to complete a Contemporary Economic Analysis. The focus of this project format is an economic question or issue that is typically found in the popular press. For example, the dissolutions of a few large US firms despite the public appearances of solvency have raised questions as to the auditors' independence from the companies they audit. Further, some have argued that the oligopolistic nature of the industry has led to higher prices for auditing services. The student that developed their capstone research project on this topic investigated whether the structure, conduct and performance of the auditing industry had changed substantially and whether this in turn could be linked to higher prices observed for auditing services.

- Quantitative Economic Analysis: Students choosing this option focus on a single economic question that can be answered using empirical analysis. Consider, for example, the degree to which corruption affects the level of foreign direct investment. Using data on 277 countries, one student estimated the impact of yearly changes in the corruption index on the level of foreign direct investment.

- Historical Economic Analysis: This option is provided for students interested in considering the historical development of an economic issue or how changes in policy have affected outcomes over time. It requires that students first identify significant historical time periods and the reasons for their importance, then interpret the issue in light of these periods. Students who are interested in historical fluctuations in oil prices consider economics 
conditions and associated policy recommendations across different time periods. The economic feasibility of expanding oil exploration in Alaska's Artic National Wildlife Refuge is a popular associated policy issue.

- Viewpoints in Economic Analysis: Students that have been exposed to different theoretical perspectives or are interested in debates across viewpoints may choose this project format. This option requires that students first provide a general understanding of Neoclassical, Keynesian, Institutionalist, Marxist and Feminist viewpoints. The issue and question that is chosen is then used to compare and contrast viewpoints on assumptions, models and policy recommendations. The issue of gender differences in wages is an example of a viable project topic.

\section{Additional examples of topics}

While students are encouraged to think of their projects within the above-defined categories, many combine them to develop a more sophisticated analysis of their topic. The most important aspect of the project is moving from a topic to developing an effective economic question that serves as the basis for research. For a discussion on the criteria that ensure an effective economic question and examples of student questions evaluated in the light of these criteria, see section 3.2.1 and Figure 2 in the chapter. Figure 6 in the accompanying chapter provides additional examples in the form of final abstracts of six student projects that describe the economic issue, implicit economic question and results in greater detail. The breadth of issues that have been developed for this course (see Figure A below) further suggest that courses requiring research projects to be linked to specific topics may actually stifle the interests and creativity of students.

Figure A Research paper titles (select titles from three years of projects)

- Can You Hear Me Now? (An Analysis of the Competitive Nature of the Cellular Phone Industry.)

$\sum$ Single Entity Sports Structure: A Monopsony's Effect on the Beautiful Game (of Soccer).

- Lessons From The Past: A Logical Estimation of President Bush's Temporary Worker Program and its Effect on the Wage Rate

- Latin America, Trade and Growth. A Cross-Country Empirical Analysis.

- Why Do Environmentalist Organizations Opt for Lobbying Over Direct Market Participation?

- Perceived Corruption and Foreign Investment: Are Investors Vigilant?

- Should They Be Mine or Should They Be Ours? (An Analysis of Public and Private Property Rights in the Chesapeake Bay Oyster Industry.)

- And Then There Were Four. (An Analysis of the Competitive Nature of the Auditing Industry.)

- Under The Gun: An Evaluation of the Richmond Virginia Project Exile.

- Dry Clean Only (An Analysis Of Protectionist Policies In The Textile Industry.)

- Human Rights versus Property Rights- Conflicting Interests In The Case Of Pharmaceuticals?

- Intelligent Athletics: The story of SAT scores' \& applications' relationship with athletics

- Is Pittsburgh a City in Decline?

- What's In Your Wallet? An Analysis of Debt Among American Families

- The Wage Premium to Marriage: Does One Exist and Why?

- Undoing the Myth behind Title IX: Both Men and Women Benefit from Title IX

- Health Care Policy: Can Medical Savings Accounts Avert Medicare's Crisis? 
- As the World Turns-An Analysis of International Impacts on China's Economy and their Affects on the United States Trade Levels

- Hanging by a Thread: An Historical Analysis of the American Textile Industry

- Success on Mount Everest: An Input Factor Analysis of the Probability of Reaching the Summit

- Balanced Teams versus One Player: The Effect of Scoring Distribution on Points Earned in Soccer

- The Visiting Dollar: Tourism and the Question of Sustainable Economic Growth

- Has Technology Changed the Game of Golf?

- The Ryan White CARE Act: Understanding the Allocation of Title II Funds

- To Increase U.S. Demand for Adoption: The 1997 Adoption and Safe Families Act

- An Economic Justification for Publicly Funding Individual Artistic Disciplines

- Listen to the Music: Identifying Demand Factors in Online Music Downloading

- Are the New England Patriots a Dynasty? A Look at Competitive Balance in the NFL

- Is the Market for Baseball Players Really “Insane?” An Analysis of Pay and Performance in Major League Baseball

- Hollywood \& the Movies: What it takes to be Number 1 at the Box Office?

- Do Sports Stadiums Impact Outcomes? An Analysis of Stadium Characteristics and Performance in the National Football League

- Quality Controlled Release Timing in the Motion Picture Industry

- Liberalizing the Divorce Code in Spain: An Analysis of the Newly Implemented Divorce Legislation

- How Does Legislation Effect Crime?: An Economic Analysis of the Virginia Shall Issue Law

- The Marlboro Man's Last Ride: A Study of the Economic Impact of Smoking Bans on Minneapolis, Minnesota And Richmond, Virginia Bars and Restaurants.

- Organ Donation: Altruism Not Making the Cut

- Is Excess Foreign Capacity Utilization Killing Inflation in the United States in the 2000s?

- Marijuana Prohibition, Up in Smoke? An Analysis of the Budgetary Implications of Marijuana Legalization in Virginia

- HIV/AIDS in South Africa: Destroying Lives and the Economy

- How Deep is America’s Oil Well? An Analysis of America’s Growing Oil Dependency and Possible Solutions

- Breaking the Addiction: A Historical Analysis of the Impact of Oil Prices on Alternative Energy Sources

- FEMA Needs a Facelift: An Analysis of Budget Management and Natural Disaster Policy

- Consumer Demand for Spa Services: An Economic Analysis of What Drives Us to Feel Good

- Tort Reform: The Answer to Rising Health Care Prices or Not?

- Competition and Consolidation in the Audit Industry: Comparing Highly Consolidated Client Industries to a Control Group

- Outsource Without Remorse? A Study of the Negative Effects of Outsourcing American Information Technology Jobs To India

- To Russia with Love: the impact of Foreign Direct Investment on Growth of CIS Countries.

- Can There Be Too Much of a Good Thing? The Economics of Contraction in Major League Baseball

- A Bubble in Baltimore Housing?

- Should California Be Farming? A Cost-Benefit Analysis of Agricultural Subsidies in California's Central Valley 


\section{Practical planning and scheduling}

The development of undergraduate research projects in a dedicated class has many challenges. The following describes three such challenges and the resultant planning and scheduling used to minimise potential problems.

1. Course Timing: This course is completely contained in a single semester, the spring semester of the student's graduation year. Students need to hit the ground running in order to complete their projects during the semester and graduate on time. Two specific activities were used to ensure that students were kept on track. First, students were invited to a meeting the semester prior to the course that described the course layout and encouraged students to begin thinking about their topics. This meeting was critical for developing the appropriate mindset for students. Secondly, the course was developed with a series of strict deadlines and required that the paper be developed (and turned in for evaluation) in stages. While students did complain sometimes that the highly structured environment was oppressive, they unanimously agreed at the end of the semester that they were not likely to have stayed on task and create a quality project without this structure.

2. Student Preparatory Skills: A second challenge of this course is that students come prepared with varying degrees of competency in the proficiencies. I developed exercises that model the research process to assess the preparatory skills that students have mastered and to have students understand their own abilities and limitations. These exercises include having students identify the economic question and supporting evidence in articles of different formats (such as qualitative and quantitative). They are asked to evaluate the evidence provided and provide an assessment of their understanding of the methods used. Students are also expected to provide detailed outlines of these articles so that they can become more familiar with the presentation style of an economics paper.

3. Developing Evidence: Despite the exposure to different forms of evidence via the sample articles, students tend to focus their efforts on the review and synthesis of literature and stumble on the development of original evidence. In fact, some students simply try to present an expanded literature review as their evidence. Since this course does not limit students to a particular topic, the problems that students face can be wide ranging. I use the one-on-one meetings, required outline of this section of the research project, and drafts associated with this section of their paper, as opportunities to evaluate each student's progress in developing the necessary evidence at various stages of the course.

\section{Evaluation evidence}

Despite these issues, the course survives because it meets the objectives of developing student competencies with respect to the proficiencies. At the end of their experience, students were asked to complete an anonymous, lengthy course evaluation in addition to the traditionally administered evaluation. The purpose of this additional evaluation was to obtain honest feedback on different aspects of the course including resources (text, assignments and instructor) and the process that guided them to their final product. Students identified choosing their topic, developing their contribution and finding relevant data as the most difficult parts of the research process. Major strengths of the course appearing throughout students' comments included learning how to do research like an economist, choosing their own topic and the feedback received throughout the process. For example, one student suggested, 'I learned how to develop a good research question. I learned how to effectively research a topic or make my own contribution to the existing knowledge base (instead of doing a "book report"').' With respect to feedback, students regularly identified the one-on-one meetings as a strength of the course.

Although many students did not identify any course weakness when asked directly, others cited not enough time, too much freedom and the magnitude of work required. For example, one 
student stated, 'It should be almost year long. Not for the writing, but for the studying. It would have been nice to continue the study before conclusions were made.' This comment also indicates, however, that students were dedicated to the research process as a result of the course. In fact, when asked to identify what they learned from the experience, nearly every student identified some component of the research process as part of what they learned. In short, they felt as if they had achieved the objectives of acting like an economist through the development and completion of their research project.

For more information about the details of this course see:

McGoldrick, KM. (2006) 'Applying the Tools They Have Mastered: The Senior Research Course in Economics' (under review). 


\section{Case Study: Service-Learning: The Application of a Non-traditional Form of Undergraduate Research within an Existing Course}

\section{Summary}

Service-learning is a method of experiential learning that links the classroom with the local community. It requires students to spend time in volunteer service and relate their experiences with the theories they learn in the classroom. Unlike classroom exercises and simulations that often deal with hypothetical problems, service-learning provides students ample opportunities to engage with the material in the context of actual issues and problems in their communities. This pedagogical technique is also unique in that it requires students to actually perform activities that economists would perform. During the service-learning project students identify economic issues, formulate hypotheses, gather evidence, develop economic explanations, link evidence relating their experiences with these economic theories and make policy recommendations. Thus, service-learning suggests an active approach to learning economic theory and conducting research. This case describes the integration of a service-learning project as an undergraduate research project developed for an existing course.

Women and Gender Issues in Economics is an elective course requiring both micro- and macroeconomic principles. It is designed to point out differences in economic circumstances between men and women. Various theories are presented in order to explain these differences and students are expected to understand as well as contrast neoclassical, Marxist, institutionalist, and feminist perspectives. Topics covered in this course are similar to those covered in a traditional labour economics course (although focused on gender differences) including the definition of work, labour force participation, earnings differentials, discrimination, health and housing, poverty and policies.

Development of the service-learning research project is perhaps best described using three critical steps of the student process: identification of issues and organisations in the community; linking economic theory to issues and community activities; presenting research outcomes; and linking across organisations and thus economic theories.

\section{Identifying the issues and organisations in the community}

The community service project begins with the student identification of an organisation that has had an economic impact on women in the local community. In this stage of the project students put their foundational knowledge to the test by identifying an economic issue and formulating a question relating to how a specific community agency addresses this issue for women in the community.

Since this is a service-learning project, students are expected to learn, in part, through their interactions with and service to the community agency. Thus, 15 hours of community service are required. During these hours the students complete a variety of task including questionnaire construction, data analysis, tutoring, resume building, etc. While the exact task is not necessarily critical to the nature of the project, it is important that the students work on a specific project from which they can learn more about the organisation, its activities and the people it services as opposed to paper-pushing activities such as filing.

Consider, for example, the issue of homelessness. In the community in which these students interact, the Emergency Shelter is the key organisation because it provides temporary shelter to homeless women and their children, assists in locating resources necessary to correct their homeless situations, and acts as an information centre in areas such as employment, housing, financial assistance and counselling. 


\section{Linking economic theory to issues and community activities}

Once students have identified a key issue and linked it to the community agency, the next stage in the research project is to begin an academic investigation of the economic perspectives regarding this particular issue. Continuing our example above, students are expected to link economic issues to the activities of the Emergency Shelter including those associated with education and skill acquisition, the human capital model, minimum wage issues, unemployment, occupational segregation, the cycle of poverty, child care, welfare policies and homelessness. Thus, students are developing skills such as undertaking and summarising a literature review, identifying an area of contribution (albeit by the community agency) and potentially analysing data.

Because the linkage of theory and practice is often a new endeavour for students, this process should include significant opportunities for formative feedback. As part of the design of this project, weekly journals are required in which students provide an update on their projects including their activities at the organisation, their thoughts on its impact and the evidence they are gathering in support of this assessment, and the status of the academic component of their research. Instructors can review these weekly reports and provide feedback for the students. Although weekly journal entries can be the sole method by which students identify relevant economic theory, develop data collection plans and describe their analysis, opportunities to share across students are also fruitful. In-class discussions that incorporate student reflections based on the projects for which topics are currently being covered provide additional opportunities for students to link theory and practice. This process also allows other students to rethink their own project development in light of the processes described by their peers.

\section{Presenting research outcomes and linking across organisations}

The final step in the service-learning research project focuses on students drawing conclusions as to the effectiveness of the community agency, linking their work to a broader policy issue and presenting their findings. Students are required to develop a 7-10 page report that includes an introduction of the organisation, details of its goals and programmes and proof of at least two economic impacts on women in the community. Students are also required to link their work with the theories discussed during the semester and investigated in their own supplemental research, evaluating this in light of broader policy perspectives. Ideally, the report includes a quantitative component that measures the impact of these programmes on the local economy. Given the considerable difficulty in obtaining such a measure, students are allowed to make an assessment of this impact via other quantifiable measurements. The number of community members served by agency programmes, the number of individuals able to find independent housing and jobs as a result of agency programmes and the budgetary records kept by the agency provide insight into the economic impact. This quantifiable component is then supplemented by a qualitative component including descriptions, verbatim quotations, etc. In this way students can draw from a wide range of evidence sources in support of their identified economic impacts.

Although the first two goals of this final step could be satisfied simply through a written report, there is significant added benefit associated with the presentation. The poster session requires students to create a summary display of their work including a description of their organisation, the programmes it provided and their statements identifying economic impacts. During this class session students shared a narrative of their experiences with classmates as well as invited faculty. The poster session also provides an opportunity for students to learn about the economic issues relating to and impacts of other community organisations. Students are encouraged to wander the room and share their experiences with classmates and to compare economic issues identified. For example, students who had volunteered at the Emergency Shelter 
are able to learn about the experiences of students who had volunteered at the Community Fitness Programme. This organisation provides services, such as financial counselling and resource identification, for those women who have moved out of the Emergency Shelter and into independent housing. During this poster session, the information exchanged about these two community organisations allows students to further explore the cycle of poverty. The integration of issues addressed by these two organisations provides a more long-run view of the steps available to break out and remain out of the cycle of poverty.

\section{Some practical issues}

To ensure the completion of the required hours of service and hold each student responsible for the assistance or task promised to the organisation, a contract detailing their service commitments is signed by the organisation staff, the student and the instructor. (An example of such a contract is provided at the end of this case study.) The formality of a contract is designed to ensure a level of accountability for the promised involvement of each student. Additionally, it makes clear to the organisation that students will be asking for information as well as providing their services. This contract is an important component of the service-learning project because it reinforces the serious nature of this work to both the student and agency and reduces the likelihood of failed projects because the relationship between the student and agency breaks down.

As with any significant research project, completing quality work in a single semester is a challenge. This is no less true in the case of a service-learning project. Additional logistical issues may arise as well including transportation to the community site and scheduling of volunteer time. Addressing these issues with students early on in the semester will minimise their impact on the project. Additional steps taken over the semester ensure that students are meeting their obligations and correct any problems that might arise. A strict timetable is provided including deadlines associated with choosing an organisation, completing the contract and service hours, turning in a final paper and developing their poster report. A mid-semester interview is also scheduled with each student to check on their progress and provide additional guidance for their papers.

\section{Evaluation}

Student reactions to the application of service-learning have been overwhelmingly positive. As one student recorded in her journal, 'I think it was a very interesting and rewarding experience. I got a look at homelessness that I never would have gotten elsewhere.' Another student suggested, 'The welfare discussions and welfare reform debates were made very real by my experience.' Other exit interview comments included, 'They are all unique - the "stereotypical" homeless person does not apply to any of the people I met. I admire their steps to get back on their own.', 'I've just finished my 15 hours tonight. I'm going to go again...because I'm having fun.... As far as the link to class goes, it's very disturbing to talk about poverty. It's so much easier to ignore its existence and live my selfish happy little life.'

Student exit interviews also suggested that although little formal incentive for further integration or application was provided, students had already considered this process. 'This experience is proving to be valuable in terms of opening my eyes up to a potential senior project for leadership studies. I would probably never have stumbled onto this opportunity as the subject for my senior thesis if it wasn't for this project!' All six volunteers at the Emergency Shelter intended to continue their volunteering beyond the course requirements.

Faculty reactions to the poster session were also overwhelmingly positive: 'A great way to engage students in their learning.'; 'A great idea to demonstrate a higher level of student participation in social/public service which affects women in society.' 


\section{Integrating Service-Learning Projects across the Curriculum}

Service-learning projects have two additional characteristics that might encourage faculty to integrate them into existing courses: they are grounded in learning theory and they come in many forms. Because the development of service-learning projects is not motivated solely through the development of an undergraduate research project, it has a wider potential for adaptation to existing courses. For example, the project described above was motivated by the desire to better link pedagogical practices to learning theory and to challenge the 'realities' attributed to standard theory; a more detailed description of such is included in McGoldrick (1998). Additionally, the wide range of forms of service-learning provides ample applications from which to choose. McGoldrick (1995) argues for the integration of four forms of servicelearning (community service, student-based instruction, action research and community problem-solving seminars) into a variety of economic courses ranging from principles to capstone courses.

A service-learning (action research) project developed for a capstone or economic theory and public policy course requires students to investigate a series of economic policy issues that have an impact on their local community. Issues related to welfare reform and the debate over national health insurance are such examples. Groups of students divide the responsibility of performing field work to identify individual and location-specific characteristics within their target community. This information is then combined with more formally presented economic theory in an assessment of the impact of economic policy changes or a plan of action for the community. For example, health care policy factors such as the extent of individual health care coverage, the availability and cost of state funded health care clinics and programmes, and current as well as proposed changes in federal, state and local health care policies are documented. Running concurrent with their field work, seminar classes develop alternative economic theories outlining the debate over national health care. Students then use these formal models to develop a plan of action specific to their community, suggesting the fiscal feasibility of state or locally funded health care facilities or documenting budgetary implications of a national health care system.

Those interested in learning more about this pedagogical technique are encouraged to review the volume edited by McGoldrick and Ziegert (2002). This text provides both a detailed presentation of the theory of service-learning specifically linked to economics and examples from those who have incorporated the practice of service-learning into their economics courses.

\section{Resources:}

Ball, D., McNabb, E. and Whitt, C. (2002) 'Getting Started in Service Learning: Resources for Economists', in McGoldrick, KM. and Ziegert, A. (eds), Putting the Invisible Hand to Work: Concepts and Models of Service Learning in Economics, Ann Arbor: The University of Michigan Press, pp. 93-118.

McGoldrick, KM. (1995) 'Service-Learning: An Application for Economics Students', unpublished paper. Presented at the IAFFE Session of the Eastern Economic Association Meetings, New York, March.

McGoldrick, KM. (1998) 'Service-Learning in Economics: A Detailed Application', Journal of Economic Education, Vol. 29(4), pp. 365-376.

McGoldrick, KM. and Ziegert, A. (eds) (2002) Putting the Invisible Hand to Work: Concepts and Models of Service Learning in Economics, Ann Arbor: The University of Michigan Press. 


\section{Appendix 1 Sample Service-Learning Contract} Source: Ball, McNabb and Whitt (2002) pp. 110-111

Course:

Faculty Contact:

Address:

Phone/email:

Total Service Hours Required:

Part I: Contact Information

A. Name

Campus Address

Home Address

(street)

(city/state/zip)

(phone)

B. Service Organisation/ Site

Name/position of supervisor

Address/phone

Your position title as volunteer

\section{Part II: The Service Activity}

A. EVALUATION: Please provide site supervisor with an evaluation form, to be returned to you by the end of semester. Include it in your portfolio for $20 \%$ of your grade.

B. JOB DESCRIPTION: Describe in as much detail as possible your role and responsibilities while service-learning. List duties, projects to be completed, deadlines, etc. if relevant.

C. SUPERVISION: Describe in as much detail as possible the supervision to be provided. What kind of instruction, assistance, consultation, etc. you will receive from whom, etc.

\section{Part III: Learning Objectives / Learning Activities}

A. LEARNING OBJECTIVES: What do you intend to learn through this experience? Be specific. Try to use concrete, measurable terms.

\section{B. LEARNING ACTIVITIES}

(1) On the Job: Describe how your service-learning will enable you to meet your learning objectives. Include projects, research, report writing, conversations, etc., which you will do while working, relating them to what you intend to learn.

(2) Off the Job: List reading, writing, contact with faculty, peer group, discussion, field trips, observations, etc., you will make and carry out which will help you meet your learning objectives.

C. EVALUATION: How will you know what you have learned, or that you have achieved your learning objectives? How do you wish to evaluate your progress toward meeting these objectives?

Part IV: Agreement

This contract may be terminated or amended by student, faculty sponsor or service site supervisor at any time upon written notice, which is received and agreed to by the other two parties.

Student Signature:

Date:

Service Site Supervisor:

Date:

Faculty Supervisor:

Date:

(Copies of this contract should be distributed to all parties) 